\title{
Observations of wave orbital scale ripples and a nonequilibrium time-dependent model
}

\author{
Peter Traykovski ${ }^{1}$ \\ Received 10 July 2006; revised 20 December 2006; accepted 19 March 2007; published 30 June 2007.
}

[1] Measurements of seafloor ripples under wave-dominated conditions from the

LEO15 site and the Martha's Vineyard coastal observatory were used to develop a

time-dependent model for ripple geometry. The measurements consisted of backscatter imagery from rotary side-scan sonars, centimeter resolution bathymetric maps from a two-axis rotary pencil-beam sonar, and forcing hydrodynamics. During moderate energy conditions the ripple wavelength typically scaled with wave orbital diameter. In more energetic conditions the ripples reached a maximum wavelength of 0.8 to $1.2 \mathrm{~m}$ and did not continue to increase in wavelength or decrease in height. The observations showed that the relict ripples left after storms typically had wavelengths close to the maximum wavelength. The time-dependent model is based on an equilibrium model that allows the ripples to maintain wavelength proportional to wave orbital diameter until a suspension threshold determined by wave velocity and grain size is reached. The time-dependent model allows the ripple spectra to follow the equilibrium solution with a temporal delay that is based on the ratio of the ripple cross-sectional area to the sediment transport rate. The data was compared to the equilibrium model, a simplified version of the time-dependent model (where the ripples were assumed to follow the equilibrium model only when the bed stress was sufficient to move sediment), and the complete time-dependent model. It was found that only the complete time-dependent model was able to correctly predict the long wavelength relict ripples and that the other approaches underpredicted relict ripple wavelengths.

Citation: Traykovski, P. (2007), Observations of wave orbital scale ripples and a nonequilibrium time-dependent model, J. Geophys. Res., 112, C06026, doi:10.1029/2006JC003811.

\section{Introduction}

[2] Small scale ripples generated by waves or the combination of waves and currents are ubiquitous features on sandy seafloors in depths where wave energy is sufficient to move sediment. A variety of laboratory experiments, field investigations, and synthesis efforts have been undertaken in order to develop models to relate ripple morphology to sediment characteristics and forcing hydrodynamics. For recent reviews of field and laboratory studies see the works of Soulsby and Whitehouse [2005] or Doucette and O'Donoghue [2003]. These efforts have largely focused on equilibrium approaches, in which the ripples are assumed to be in equilibrium with the hydrodynamic forcing. However, some of the field studies [e.g., Traykovski et al., 1999] have shown that there are significant periods during active conditions (sufficient energy to mobilize seafloor sediment) when ripples are not in equilibrium with the forcing hydrodynamics. The recent laboratory experiments by Davis et al. [2004] and Testik et al. [2005] have also

\footnotetext{
${ }^{1}$ Applied Ocean Physics and Engineering Department, Woods Hole Oceanographic Institution, Woods Hole, Massachusetts, USA.

Copyright 2007 by the American Geophysical Union. 0148-0227/07/2006JC003811\$09.00
}

focused on ripples that were not in equilibrium with hydrodynamic forcing conditions. All the field and laboratory studies have shown that ripples will not be equilibrium with the hydrodynamic conditions when the energy at the seafloor is insufficient to move sediment (subcritical stress conditions). The morphology of the ripples at the transition from active to subcritical conditions, which will determine the characteristics of the ripples preserved under subcritical conditions (relict ripples), has received less attention, especially in regards to analysis of field measurements, despite the importance of the state of preserved ripples.

[3] For sediment transport processes, ripple morphology during active conditions is most important; however, the state of relict ripples left after a storm is important for several reasons. The roughness of the seafloor, as determined by the relict ripples, can be an important parameter in the bottom boundary condition for modeling waves [Ardhuin et al., 2002; Ardhuin et al., 2003] and mean flow [Grant and Madsen, 1986] during subcritical conditions. The morphology of relict ripples can also be important for biological and chemical processes. Pore water flow through ripples has been shown to be an important mechanism for exchange of nutrients and chemicals in the upper few centimeters of the seabed [Precht and Huettel, 2004]. The state of relict ripples immediately after the transition 
to subcritical conditions is the initial condition for subsequent ripple degradation processes, which are often biologically controlled by a variety of burrowing organisms [Wheatcroft, 1994]. Ripples have also recently been shown to enhance the amount of acoustic energy that penetrates into the seafloor at subcritical acoustic grazing angles [Chotiros et al., 2002; Jackson et al., 2002]. Since the use of acoustics to detect buried objects usually occurs in subcritical conditions, the morphology of relict ripples is of first order importance to these issues. Finally, small-scale stratigraphy preserved in the geologic rock record can be a product of ripples buried during active or subcritical conditions. Thus understanding the relationship between hydrodynamic forcing and ripple morphology throughout the time history of a ripple formation-preservation event is crucial to interpreting the geological record [Clifton and Dingler, 1984].

[4] In order to increase our ability to quantify the relationship between ripple morphology and hydrodynamic forcing this paper examines the use of a time-dependent ripple morphology model that does not assume the ripples are in equilibrium with the forcing. This model builds on work based on recent laboratory experiments, in which the investigators examined the response of ripples to rapidly changing hydrodynamic forcing [Davis et al., 2004; Testik et al., 2005]. In a similar manner to the work of Davis et al. [2004], we use a spectral approach to characterize ripple parameters, as recently developed instrumentation allows us to measure the elevation spectra of the ripple as a function of wave number. Parameters such as ripple height and wavelength can be calculated from the spectra. In this paper the model results are compared to several field data sets from the LEO15 site offshore of southern New Jersey and the Martha's Vineyard Coastal Observatory (MVCO) site. The analysis in this paper is restricted primarily to a certain type of ripples, often called wave orbital ripples, because they have wavelengths that scale with the wave orbital diameter [Clifton and Dingler, 1984; Wiberg and Harris, 1994]. In continental shelf environments with energetic waves, these ripples are generally found in coarser sands with median grain diameters $\left(D_{50}\right)$ larger than $0.35 \mathrm{~mm}$, and they typically have wavelengths ranging from 0.30 to $1.5 \mathrm{~m}$ [Traykovski et al., 1999]. The larger forms of these ripples are sometimes referred to as long-wave ripples (LWR) [Williams et al., 2005], but the wave orbital ripples considered here are steeper [with height $(\eta)$ over wavelength $(\lambda)$ ratios of 0.12 to 0.2 ] than other low amplitude long wavelength bed forms also called (LWR) [Hanes et al., 2001]. These coarse sand orbital ripple range in wavelength from $0.3 \mathrm{~m}$ [which would be termed short wave ripples (SWR) in the SWR-LWR nomenclature] to LWR wavelengths of $1.5 \mathrm{~m}$, while maintaining a relatively constant ratio of orbital diameter to ripple wavelength during equilibrium conditions. Thus in this paper, they are referred to as wave-orbital scale ripples. The motivations for considering primarily orbital scale ripples in the development of the time-dependent model are: (1) the relationship between hydrodynamic forcing and ripple morphology is fairly well defined when the ripples are in equilibrium with the forcing and (2) larger orbital scale ripples are most likely to be out of equilibrium with hydrodynamic forcing. Other types of ripples are sometimes defined as anorbital and suborbital ripples [Wiberg and Harris, 1994]. Anorbital ripples occur primarily in fine sands and maintain a constant wavelength in low stress conditions during changing orbital diameters. While the relation between hydrodynamic forcing and ripple morphology is fairly well defined for anorbital ripples in low-stress conditions, in moderate- to high-stress conditions fine sand ripples go through a complicated sequence of three-dimensional morphologies (for example, the irregular ripples, cross ripples, linear transitional ripples, megaripples, and flat bed states as documented by Crawford and Hay [2003], Hay and Mudge [2005], Hay and Wilson [1994], Smyth and Hay [2002]), which are more complicated than coarse sand ripples in the orbital scale regime. While these transitions may be complicated, based on the study of Hay and Mudge [2005] (see their Figure 14), the transitions occur approximately in equilibrium with hydrodynamic forcing.

\section{Observations}

\subsection{Site Background, Observation Techniques, and} Hydrodynamic Forcing

\subsubsection{LEO15}

[5] The first data set was taken during September 1995 at the LEO15 site in $11 \mathrm{~m}$ water depth [Traykovski et al., 1999]. This site is located on the crest of an oblique shorefaced attached ridge; the sand grain diameters on the crest are medium to coarse with $D_{50}$ of 0.3 to $0.5 \mathrm{~mm}$ and are moderately to moderately well sorted [Craghan, 1995]. The hydrodynamic forcing during the deployment was characterized by a series of tropical storms that passed well offshore of the study site and generated low amplitude [significant wave heights $\left(H_{1 / 3}\right)$ of 0.6 to $1.2 \mathrm{~m}$ ], relatively long-period waves (10 to $16 \mathrm{~s}$ ) (Figure 1). Hydrodynamic parameters were calculated from Benthic Acoustic Stress Sensor (BASS) current meters as described by Traykovski et al. [1999]. These waves generated near-bed wave velocities of 0.2 to $0.3 \mathrm{~m} / \mathrm{s}$ and wave orbital diameters of 0.3 to $2 \mathrm{~m}$ at the seafloor. Mean currents in the across-shore direction were mainly due to semidiurnal tides and were relatively weak with velocities of 0.05 to $0.08 \mathrm{~m} / \mathrm{s}$. In the alongshore direction mean currents of 0.05 to $0.20 \mathrm{~m} / \mathrm{s}$ were due to combination of tides and longer timescale (2-3 day) processes such as the synoptic weather patterns. As is typical for shelf environments with weak to moderate strength currents, the stress at the seafloor during wave events energetic enough to mobilize sediment was dominated by the waves. The mean currents typically contributed less than $10 \%$ to the combined stress [Traykovski et al., 1999]. Here wave events are defined as the 1- to 3-day periods with wave energy sufficient to mobilize sediment at the seafloor. The 10-day period (days 240-259) of elevated wave energy in the LEO15 data set can be considered as one wave event, although these waves persist longer than the typical stormgenerated waves. The wave stress $\left(\tau_{\mathrm{w}}\right)$ is calculated using the Swart [1974] friction factor $\left(f_{\mathrm{w}}\right)$ and a roughness defined by $2.5 D_{50}$

$$
\tau_{\mathrm{w}}=\frac{1}{2} \rho_{\mathrm{w}} f_{\mathrm{w}} u_{\mathrm{br}}^{2}
$$



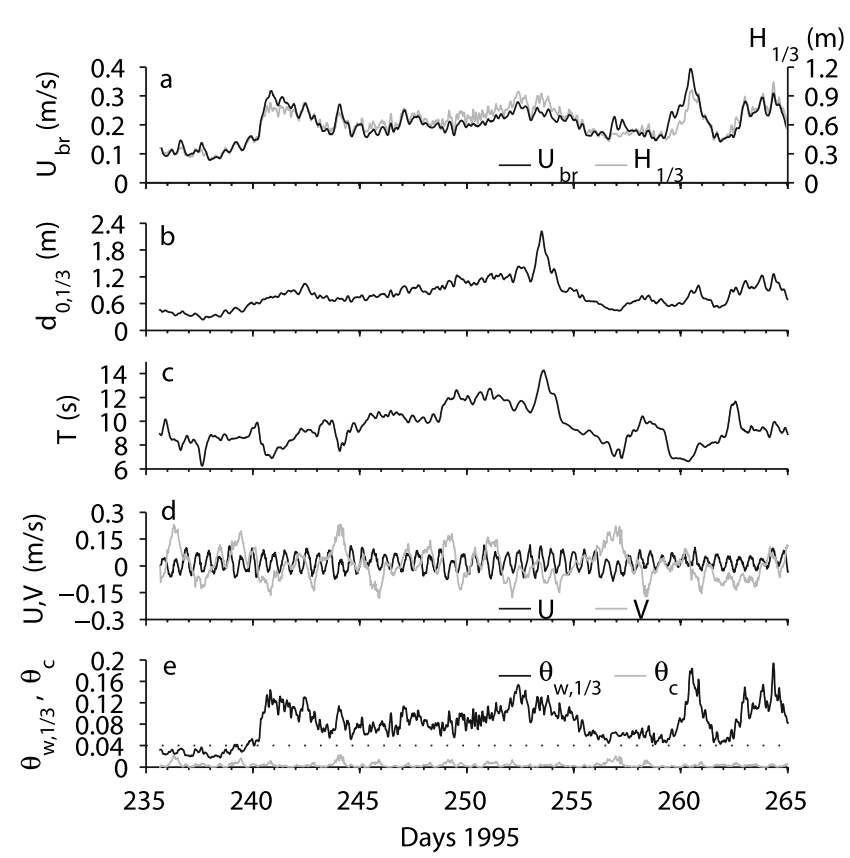

Figure 1. Hydrodynamic forcing parameters from the LEO15 Deployment. (a) Wave height (gray line, right $y$ axis) and wave velocity (black line, left $y$ axis). (b) Orbital diameter. (c) Wave period. (d) Near-bed mean current velocity (across-isobath velocity, $U$ : gray line, along-isobath velocity, $V$ : black line). (e) Wave (black line) and current (gray line) Shields parameter. The dotted line represents the critical shield parameters of 0.04 .

where the representative wave velocity $\left(u_{\mathrm{br}}\right)$ is calculated from the r.m.s. of the measured wave velocities by $u_{\mathrm{br}}=$ $\sqrt{2} u_{\mathrm{w}, \mathrm{rms}}$. For this study, wave orbital diameter based on significant wave properties was calculated by $d_{0,1 / 3}=$
$4 u_{\mathrm{w}, \mathrm{rms}} / \omega_{\mathrm{r}}$, where $\omega_{\mathrm{r}}$ is the radian wave frequency calculated from the first moment of the velocity spectral components $\left(u_{\mathrm{w}, \mathrm{i}}^{2}\right)$

$$
\omega_{\mathrm{r}}=\frac{\sum \omega_{\mathrm{i}} u_{\mathrm{w}, \mathrm{i}}^{2}}{\sum u_{\mathrm{w}, \mathrm{i}}^{2}}
$$

[Madsen et al., 1988]. This calculation was found to produce similar estimates of $d_{0,1 / 3}$ as the method by Traykovski et al. [1999]. A stress $\left(\tau_{\mathrm{w}, 1 / 3}\right)$ associated with the significant wave velocity $\left(u_{\mathrm{b}, 1 / 3}=2 u_{\mathrm{w}, \mathrm{rms}}\right)$ was also calculated by using $u_{\mathrm{b}, 1 / 3}$ in place of $u_{\mathrm{br}}$ in equation (1). The Shields parameter due to waves was calculated from the ratio of the wave stress to the immersed weight of the sediment.

$$
\theta_{\mathrm{w}}=\frac{\tau_{\mathrm{w}, 1 / 3}}{\rho(s-1) g D_{50}}
$$

As described by Traykovski et al. [1999], when the Shields parameter calculated using the significant wave velocity exceeded a critical Shields parameter of 0.04, ripples appeared to change in response to changing wave conditions. During the LEO15 deployment, this occurred during the extended period between yeardays 238 and 265. During conditions in which the Shields parameter was below this critical threshold no changes to ripple morphology were observed.

[6] During the LEO15 experiment, a Mesotech-Simrad rotary side-scan sonar [Traykovski et al., 1999] was mounted on a tripod to image ripple morphology. This system provides a plan view of ripple morphology based primarily on the angle of the insonified surface relative to the sonar, and thus does not give an estimate of ripple elevation at all points in the image (Figure 2). Because of mounting height of $1.0 \mathrm{~m}$ above the seafloor and the $2.5-\mathrm{MHz}$ transmission frequency this sonar produced

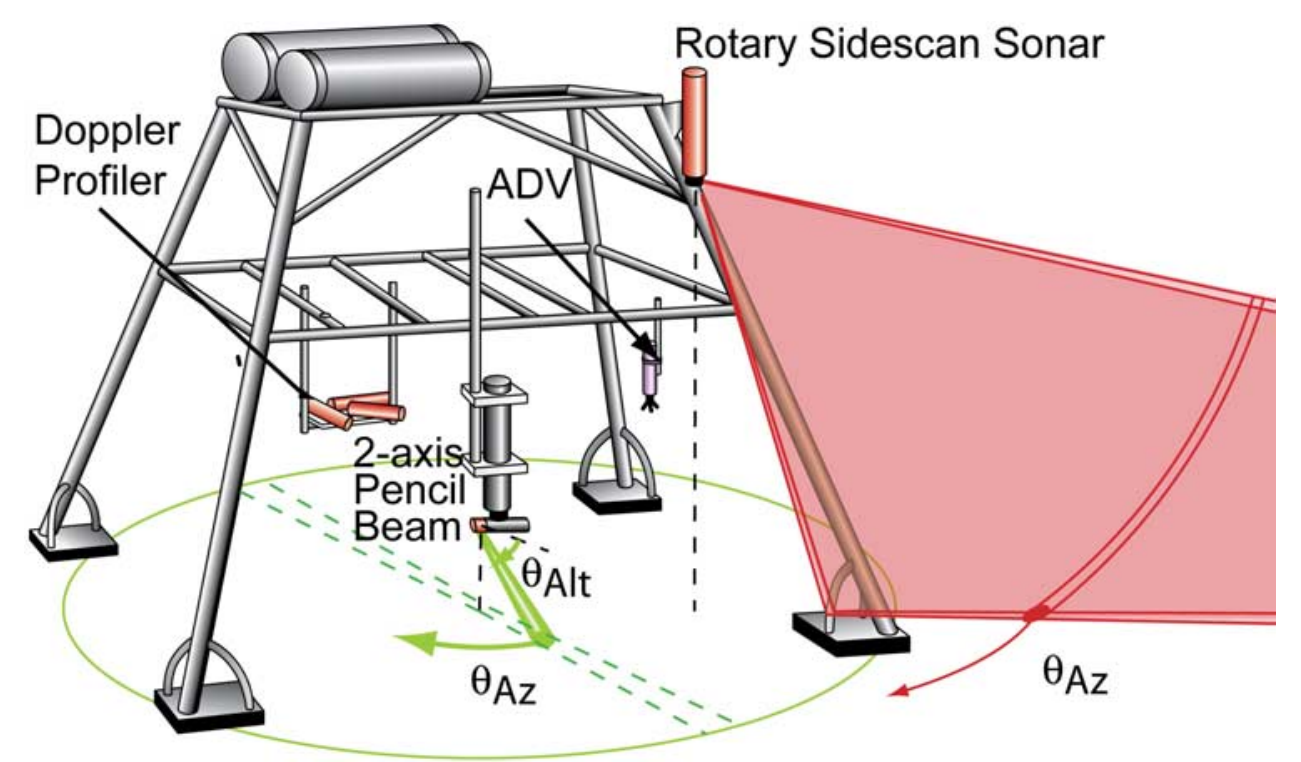

Figure 2. Schematic of quadpod deployed at MVCO during fall 2005 showing the rotary side scan and 2 -axis pencil beam sonar systems that were used to measure ripple morphology. Altitude and Azimuthal angles of rotation are denoted by $\theta_{\mathrm{Alt}}$ and $\theta_{\mathrm{Az}}$. 

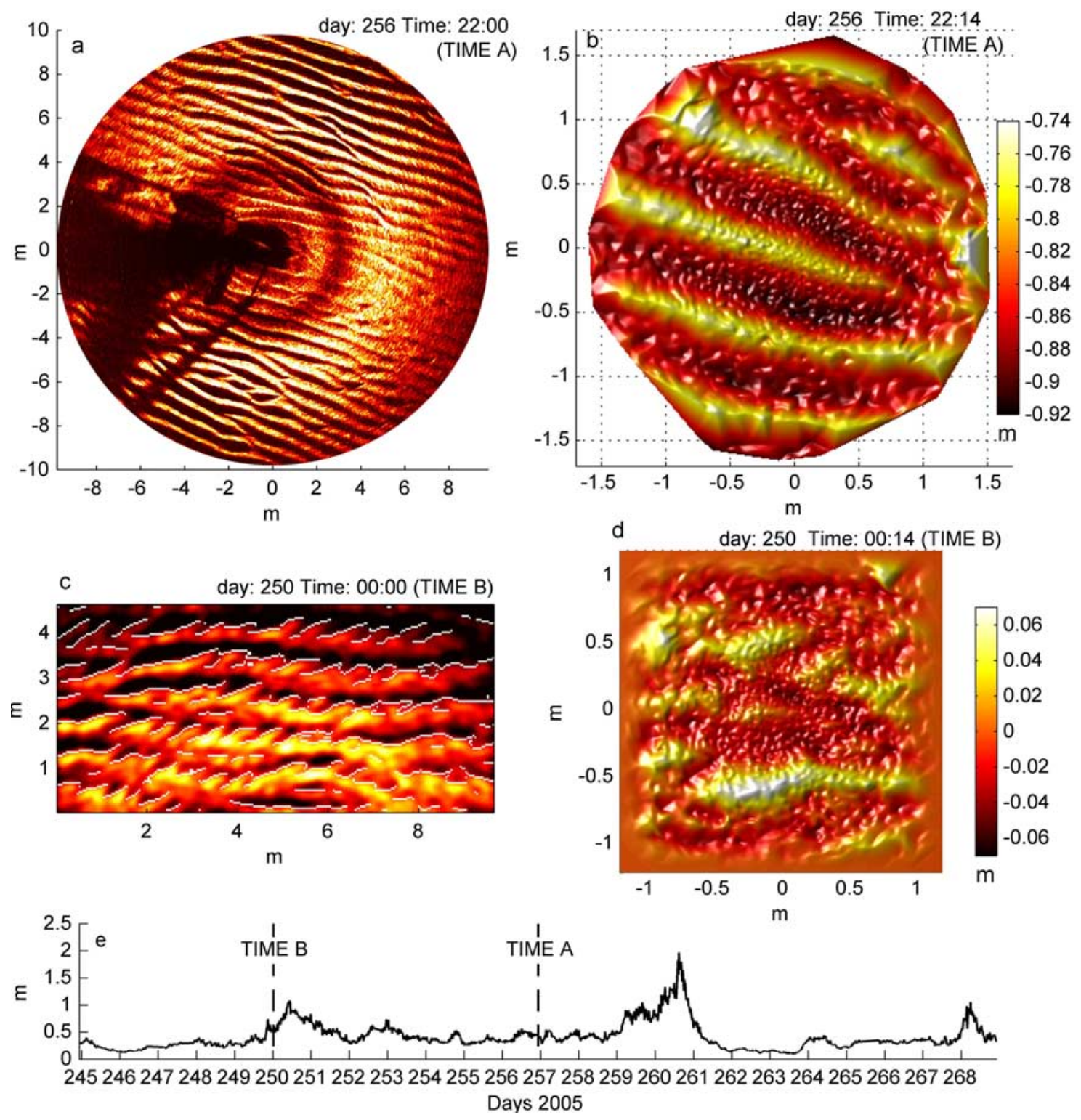

Figure 3. Ripple images from ( $\mathrm{a}$ and $\mathrm{c}$ ) the rotary side-scan sonar and ( $\mathrm{b}$ and $\mathrm{d}$ ) the 2-axis pencil beam sonar, deployed during MVCO05. A time series of (e, dashed lines) wave heights shows time A when ( $a$ and $b$ ) unimodal spectra images were taken and time $\mathrm{B}$ when $(\mathrm{c}$ and d) the bimodal spectra images were taken. In Figures $3 a$ and $3 b$ the complete imaged area from each sensor is shown for the ripples at time A. In Figures $3 \mathrm{~b}$ and $3 \mathrm{~d}$ a subset of the imaged area from time $\mathrm{B}$ that was used for processing is shown. The detected crests of ripples are shown as white lines in Figure 3c.

images with 7-m diameter of useful data. The system produces images relatively quickly (20 to $50 \mathrm{~s}$ per unaveraged image, depending on range settings), as all range cells are insonified by a single ping at a given azimuthal angle. In the work of Traykovski et al. [1999] a manual image processing technique was employed to measure ripple wavelength and direction, and an estimate of ripple height was calculated from the intersection of the rotary side-scan beam pattern with the seafloor in an approximately $1-\mathrm{m}$ radius circle under the sonar. In this paper, an automated technique based on an edge detection scheme was employed to measure ripple wavelength and direction (Figure 3c, with 20-m image diameter data from MVCO05 as discussed in section 2.1.3). The use of the automated technique ensures all data sets are processed in a consistent manner and avoids tedious manual processing. Because of the unusable data region at the center of each image for the LEO15 data a 3- by 2-m area of the image was extracted for edge detection analysis. The long axis of the 3- by 2-m area was aligned with the ripple crests. Since the rotary side-scan system does not measure topography and the crest perpendicular dimension of the usable area for processing was relatively short $(2 \mathrm{~m})$ compared to maximum ripple wavelengths of $1.3-\mathrm{m}$ edge detection analysis was used rather than spectral techniques. For the 20 -m diameter imagery in Figure $3 \mathrm{c}$ the extracted section was $10 \times 5 \mathrm{~m}$. For this data 

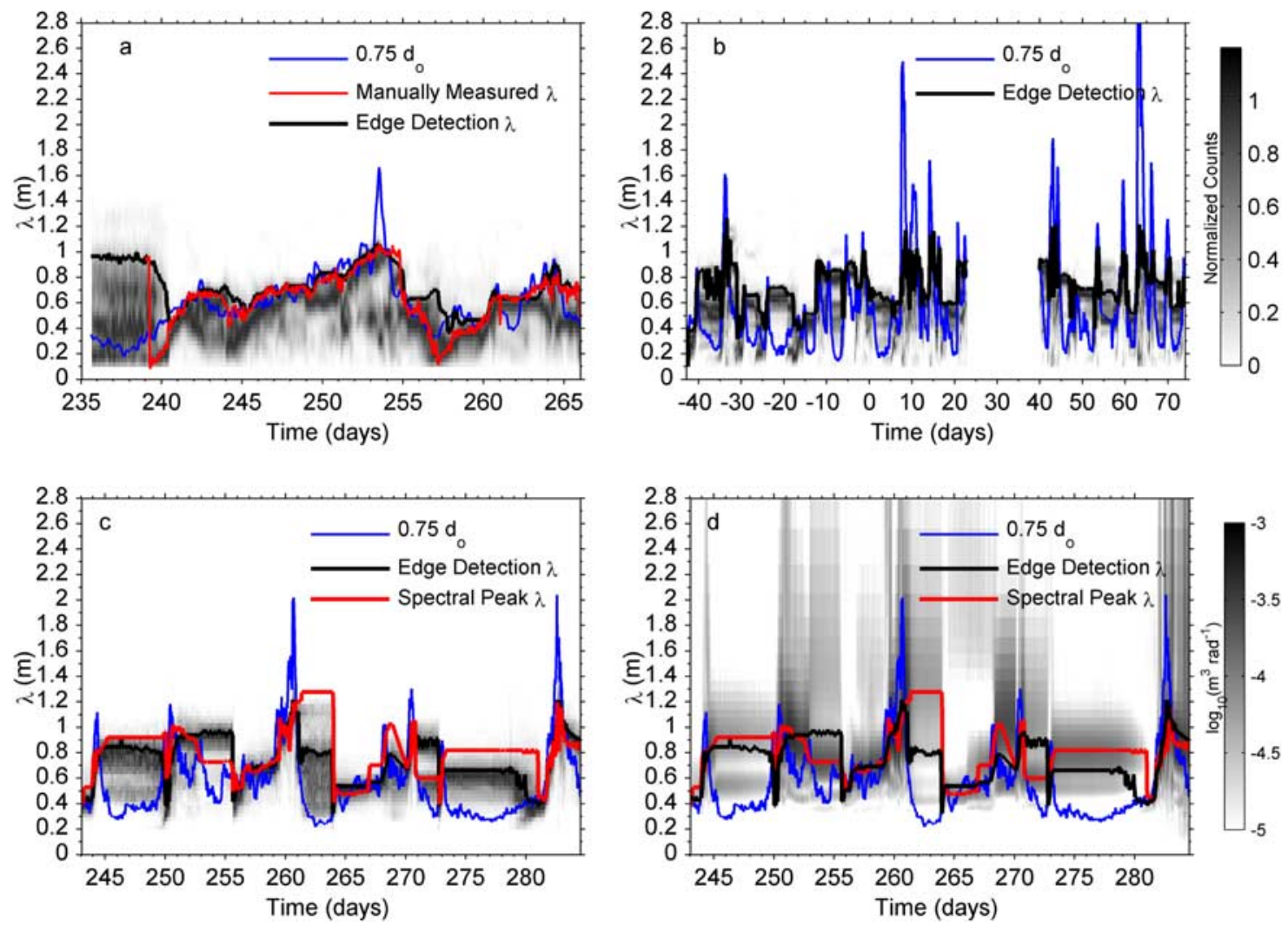

Figure 4. Time series of ripple wavelength estimates (red and black lines) shown together with wavelength histograms based on edge detection of rotary side-scan data [gray scale shading in (a) LEO15, (b) MVCO02, and (c) MVCO05) and spectra from the 2-axis pencil beam data (gray scale shading in d) MVCO05] as function of time and wavelength. The 85th percentile estimate of wavelength is shown as a solid black line, and the spectral peak estimate of wavelength is shown as a red line for (c and d) the MVCO05 data set. The scaled orbital diameter $\left(0.75 d_{0,1 / 3}\right)$ is shown as a blue line. This quantity is similar to the equilibrium ripple model, but without the transition to suborbital ripples. (a) The LEO15 data set also includes the manual detection method from Traykovski et al. [1999] shown as a red line.

set either edge detection analysis or spectral techniques could be used. However, edge detection was also used on that data so that all the rotary side-scan data was processed in consistent manner. The edge detection scheme is similar to that employed by Smyth and $L i$ [2005], and it was found that slight variations in the technique did not lead to significant differences in the ability to detect the crest of the image. The accuracy of the edge detection is on the order of the pixel size $(0.2$ to $0.5 \%$ of the range of the sonar, or 1 to $5 \mathrm{~cm}$ for the LEO15 data set [Traykovski et al., 1999]). To estimate wavelengths from the detected edges, differences in the locations of adjacent crests were calculated in the crest perpendicular direction. These distances were used to produce a histogram of ripple wavelength from which a single ripple wavelength was estimated from the 85 th percentile of the histogram. The results from the edge detection technique and the manual technique are generally fairly similar, partly as a result of the choice of the "85th percentile" definition of wavelength in the analysis of the histograms. The most pronounced differences between the computational technique and the manual technique occur during transitional periods from a long wavelength ripple to a short wavelength ripple or vice versa, since the manual technique had a subjective determination of the exact time of the transition (for example, day 240 in Figure 4a).

\subsubsection{MVCO 2001-2002}

[7] The second data set used in this study was taken as part of the Office of Naval Research Mine Burial Prediction experiments at MVCO. During the winter of 2001-2002 the same rotary sonar used in the LEO15 work in was deployed in coarse sand at MVCO [Richardson and Traykovski, 2002]. The sonar, along with a Nortek Vector acoustic Doppler velocimeter, was mounted on a $2.5-\mathrm{m}$ pole jetted approximately $1 \mathrm{~m}$ into the seafloor, so that the rotary side-scan transducer was $1.4 \mathrm{~m}$ above the seafloor, and the Vector sampling volume was $2.1 \mathrm{~m}$ above the seafloor (see Figure 3 of Richardson and Traykovski [2002], for a similar mounting of an Imagenex rotary side-scan sonar). This deployment also produced images with 7-m diameter of useful data.

[8] The MVCO site has both coarse and fine sand near the 12-m node, which supplies power and real-time data communication from the shore [Austin et al., 2000]. The variability in grain size is due to a series of rippled scour depressions (RSDs, Goff et al. [2005]) which are alternating swaths of coarse and fine sand approximately $150 \mathrm{~m}$ wide in 

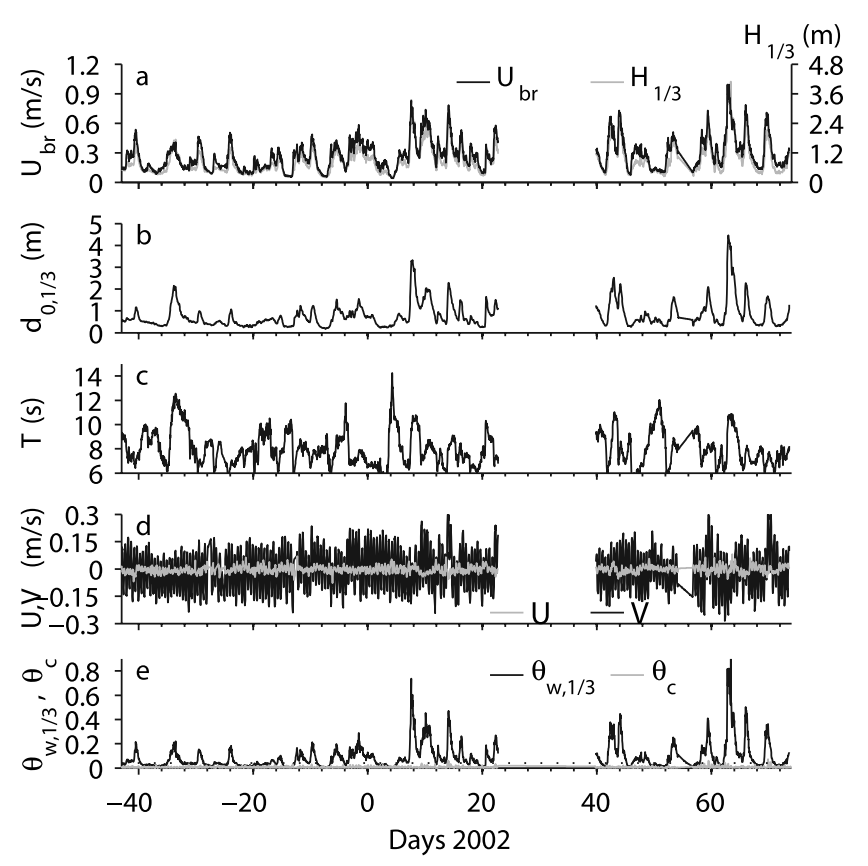

Figure 5. Hydrodynamic forcing parameters from the MVCO 2002 Deployment. The gap in the data between days 23 and 40 was due to an equipment malfunction. The quantities and line types in each plot are the same as in Figure 1.

the vicinity of the MVCO node. The deployment location in 2001-2002 was $150 \mathrm{~m}$ to the east of the MVCO node in coarse sand at a depth of $13.8 \mathrm{~m}$. The grain size in coarse areas of the RSD is coarsest ( $D_{50}$ of 0.65 to $0.90 \mathrm{~mm}$ ) near the transitions to fine sand and slightly finer near the center ( $D_{50}$ of 0.5 to $\left.0.6 \mathrm{~mm}\right)$. The median grain diameter $\left(D_{50}\right)$ of four grab samples taken within $20 \mathrm{~m}$ of the location of the sonar was $0.640 \mathrm{~mm}$ so this value was used for calculations from this data set.

[9] The hydrodynamic forcing during this experiment was characterized by a series of smaller wave events in the fall and early winter (before day 15, 2002 orbital diameters were typically less than $2 \mathrm{~m}$ ), but with sufficient energy to occasionally mobilize bottom sediment, followed by a series of higher energy events in the winter with wave orbital diameters in excess of $2 \mathrm{~m}$ (Figure 5). The two most energetic wave events have Shields parameters of 0.5 to 0.7 , which is considerably higher than the maximum of 0.15 to 0.2 at LEO15. Mean currents were characterized by slightly larger alongshore tidal velocities than LE015 $( \pm 0.2 \mathrm{~m} / \mathrm{s}$ at MVCO), combined with longer timescale alongshore flows and relatively weak across-shore flows. Despite the slightly larger currents, bed stress was still dominated by the wave velocities. The hydrodynamic parameters were calculated from the Nortek Vector velocimeter data in a similar manner to the processing of the BASS data from the LEO experiment. The MVCO node malfunctioned for a period between yeardays 23 and 40, thus there is no data available for this time.

\subsubsection{MVCO 2005-2006}

[10] In September through April of 2005-2006 an instrumented frame (quadpod) with two systems to measure ripple morphology was deployed in coarse sand $120 \mathrm{~m}$ west of the MVCO node at a depth of $12.7 \mathrm{~m}$ (Figure 2). The median grain diameter $\left(D_{50}\right)$ of two grab samples taken within $10 \mathrm{~m}$ of the location of the quadpod was $0.75 \mathrm{~mm}$. An Imagenex 881 rotary side-scan sonar was mounted on the corner of the frame $2.2 \mathrm{~m}$ above the seafloor. This higher elevation than the previous deployments combined with the adjustable range setting on the Imagenex sonar versus the fixed 5-m range of the Mesotech-Simrad sonar, allowed a larger field of view (10-m radius image as opposed to 3 to $4 \mathrm{~m}$ ) at the expense of lower resolution (also approximately a factor of 2). The quadpod also had an Imagenex $881 \mathrm{a}$ pencil beam (with $\pm 1.4^{\circ}$ beam width as defined by half power points) sonar with two stepper motors to control the sonar orientation. As opposed to the rotary side-scan system, this sonar only insonifies one range bin on the seafloor per ping (Figure 2). Thus the stepper motors were activated sequentially so that the system imaged a vertical slice by stepping the altitude angle $\left(\theta_{\text {alt }}\right)$ drive with $1.2^{\circ}$ steps. This generated intensity images as a function of both range from the transducer and altitude angle. The resolution in range was determined by the $1-\mathrm{cm}$ range bins selected for this deployment. After each slice was imaged, the azimuthal stepper motor was activated to rotate the sonar $3^{\circ}$ in $\theta_{\mathrm{Az}}$. The transducer was mounted $0.90 \mathrm{~m}$ above the nominal seafloor, and was typically able to image out to $60^{\circ}$ in $\theta_{\text {alt }}$, resulting in microtopographic maps with $3-\mathrm{m}$ radius and $2-\mathrm{cm}$ horizontal by $1-\mathrm{cm}$ vertical resolution near the center, decreasing to $10-\mathrm{cm}$ horizontal and $5-\mathrm{cm}$ vertical resolution near the edges. Subsequent data processing calculates the location of the ripple surface in each azimuthal slice, which was then gridded with $1-\mathrm{cm}$ horizontal resolution (Figure 3d). A two-dimensional FFT was then performed on the gridded surfaces to calculate surface elevation spectra as a function of wave number, and the peak of the spectra were used to estimate wavelength and direction of the ripples. The integral of spectral energy under the peak was used to estimate representative ripple height $\left(\eta_{\mathrm{r}}\right)$ with a scaling factor of 4 similar to that used to calculate significant wave height:

$$
\eta_{r}=4 \sqrt{\iint \eta(k)^{2} d k_{x} d k_{y}}
$$

The integral was computed on a surface bounded by a contour located at $1.5 \times 10^{-5} \mathrm{~m}^{3} / \mathrm{rad}$ in order to eliminate high frequency noise from the height estimate. This technique was found to agree reasonably well with a peak to trough estimate defined by the 2nd and 98th percentile of the elevation distribution. Since each azimuthal slice takes $22 \mathrm{~s}$, and the total map takes $22 \mathrm{~min}$, it was not possible to perform any averaging of images within the hourlysampling schedule. The rest of the hour was dedicated to sampling other instrument systems with the same data acquisition system as the 2-axis sonar. Since each rotation of the Imagenex 881 rotary side-scan sonar takes $25 \mathrm{~s}$, the 881 data logger averaged eight sequential full rotations of the sonar data with $30 \mathrm{~min}$ between averages. The lack of averaging in the 2-axis sonar data combined with the decreased resolution at larger altitude angles results in spectra that decrease linearly (i.e., a red noise floor) at wave numbers greater than $30 \mathrm{rad} \mathrm{m}^{-1}$, which makes ripples with 

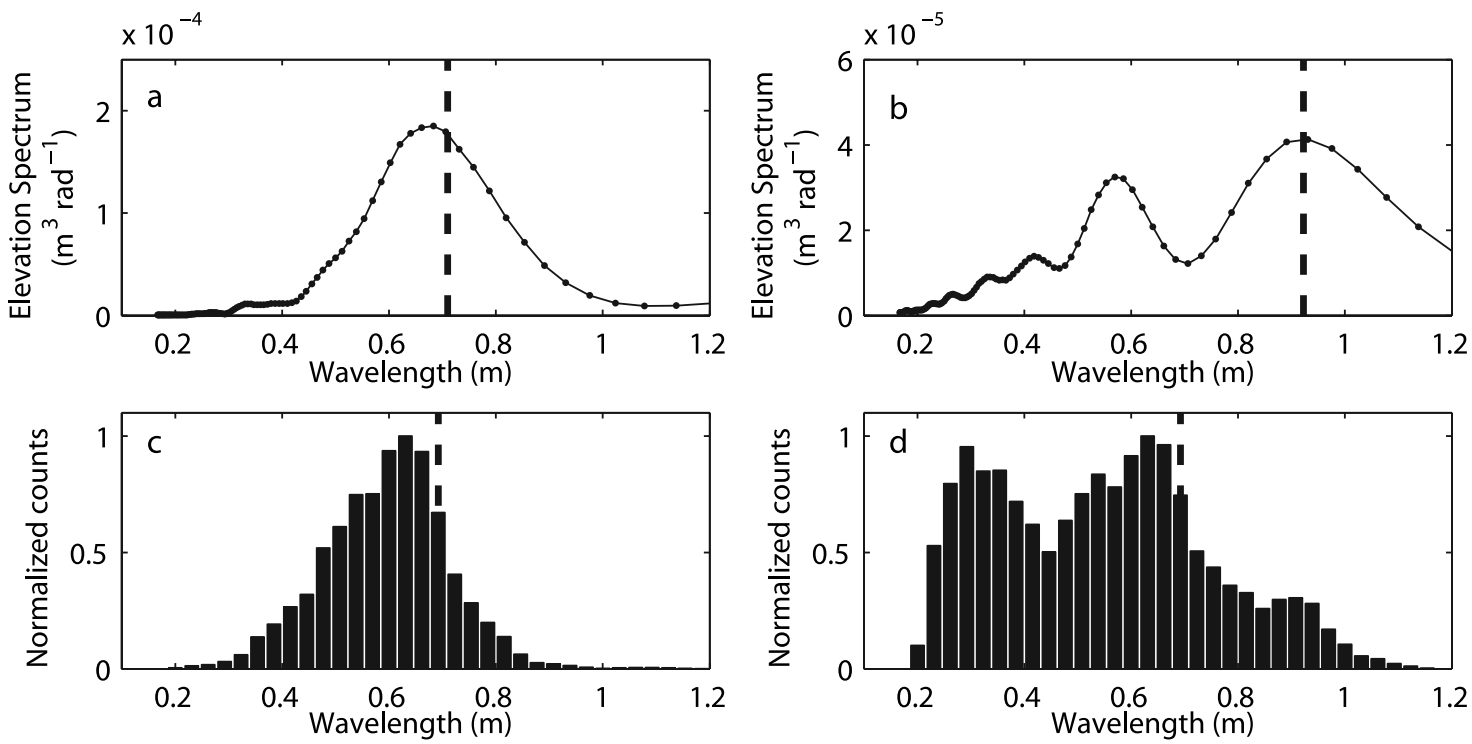

Figure 6. ( $\mathrm{a}$ and $\mathrm{b}$ ) Spectra and ( $\mathrm{c}$ and d) histograms from time A in Figure 3 with (a and c) unimodal spectra and from time $\mathrm{B}$ with ( $\mathrm{b}$ and $\mathrm{d}$ ) bimodal spectra.

wavelengths less than $0.20 \mathrm{~m}$ difficult to resolve. For measuring anorbital ripples this could be improved by about a factor of two by only using data from the center $\left(\theta_{\text {alt }}<40^{\circ}\right)$ of the sampled area, which has higher resolution at the expense of smaller sampling area. For the large orbital ripples at this site the lower resolution was acceptable; however, for smaller ripples, the higher resolution data in the center of the sampling area would be required. Useful data was collected from both the rotary fan beam sonar and the 2axis pencil beam system until yearday 285 , when biofouling significantly degraded the imagery. While the 2-axis pencil beam spectral estimates of ripple wavelength and rotary sidescan edge detection estimates of ripple wavelength are generally quite similar, at times there are significant differences (Figure 3 and Figure 6). The times with significant differences occur usually when multiple ripple wavelengths are present, i.e., both the histograms are broad or bimodal and the spectral bandwidth is large, or bimodal spectra are present. There does not appear to be a bias in one technique versus the other during unimodal conditions. During bimodal conditions the edge detection scheme is biased toward short wavelengths due to the fact that the distance between successive detected ripple crests is shortened by the presence of the short wavelength ripples (Figures $3 c$ and $6 b$, and $6 d$ ), because the edge detected crests of the short wavelength ripples are not treated differently from the edge detected crests of the long wavelength ripples. In the future, an algorithm for calculating the distance between detected crests that has an ability to distinguish small ripples that are oblique to larger ripples should be developed to eliminate these biases during periods of bimodal spectra; however, this is not a trivial development. In Figure 6 and subsequent figures, the two-dimensional wave number spectra are converted to one-dimensional spectra for ease of visualization by integrating the spectra over all angles.

[11] The choice of the 85 th percentile for the wavelength estimate from the histograms was also a result of compar- ison with the spectral peak estimate during periods with unimodal ripples. The 50th percentile results in wavelength estimate of that is considerably shorter than the spectral peak. Higher than 85 th percentile estimates sometimes are in better agreement with the spectral peak, but become sensitive to the long wavelength outliers.

[12] The data presented in Figures 3 and 6 to demonstrate the differences between instruments was also chosen since they represent two interesting examples of ripple morphology. The data during time period A was selected during a 5 -day period of relatively constant wave forcing in which the $68-\mathrm{cm}$ wavelength, $14-\mathrm{cm}$ height ripples were in equilibrium with the forcing. The ripples are relatively long crested and have unimodal spectra (Figures $6 a$ and $6 \mathrm{c}$ ).

[13] The data during time period $B$ shows a typical example of a bimodal spectrum at the beginning of a wave event. On days 246 through 250, ripples with a wavelength of $0.93 \mathrm{~m}$ were present from a previous wave event on day 245 with an additional spectral component at $0.47 \mathrm{~m}$, (Figure 4d). The ripples associated with both of these spectral peaks were oriented in a SSW direction consistent with the forcing from the previous wave event. On day 250 a new wave event with waves from the SSE begins to form new shorter wavelength ripples superimposed on the previous ripple field. These new ripple had a wavelength of $0.55 \mathrm{~m}$ due to the orbital diameter of the new waves, but an orientation to the SSE as can be clearly seen in rotary sidescan imagery (Figure 3c) and in the resulting bimodal wave number spectra (Figure 6b) calculated from the 2-axis sonar data (Figure 3d).

[14] The hydrodynamic forcing during the MVCO 2005 deployment was similar to the forcing in the beginning of the 2001-2002 deployment, with peak wave heights of 2 to $3 \mathrm{~m}$ during events, resulting in orbital velocities of 0.3 to $0.5 \mathrm{~m} / \mathrm{s}$, peak orbital diameters of 1 to $2 \mathrm{~m}$, and Shields parameters of 0.1 to 0.3 (Figure 7). During this deployment the Vector velocimeter experienced problems with interference from other systems of the frame during some non- 

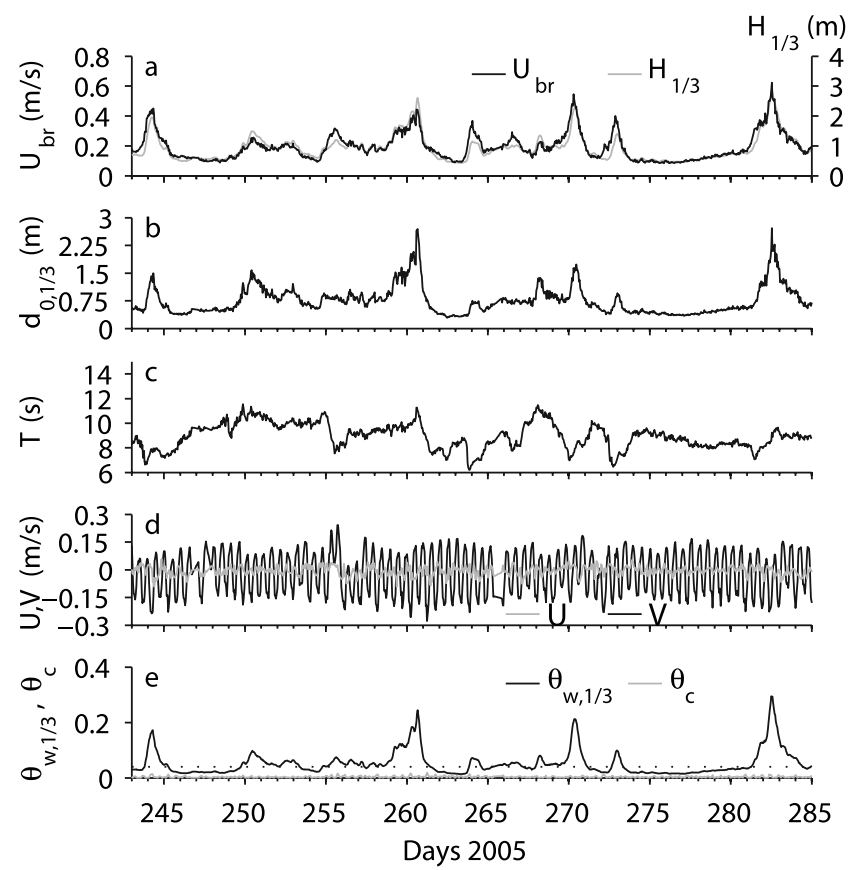

Figure 7. Hydrodynamic forcing parameters from the MVCO 2005 Deployment. The quantities and line types in each plot are the same as in Figure 1.

energetic conditions, thus the Acoustic Doppler Current Meter (ADCP) on the 12-m depth MVCO node was used to calculate hydrodynamic parameters. $U_{\mathrm{w}, \mathrm{rms}}$ at the seafloor was calculated from spectra at lowest bin [3.2 mab (meters above bed)] of the ADCP data which was translated to the seafloor using linear wave theory. Wave period at the seafloor was calculated in a similar manner to equation (2) using the spectra derived from the ADCP beam velocity data [Terray et al., 1997], which was also translated to the seafloor using linear wave theory.

\subsection{Results and Discussion of Observations}

\subsubsection{Temporal Evolution of Ripple Wavelength}

[15] Time series of ripple wavelength histograms (Figures 4a, 4b, and 4c) and spectra (Figure 4d) show episodic changes in ripple wavelength associated with energetic wave events. Typically the ripple wavelength adjusts fairly coherently with wave orbital diameter at the beginning of wave events with moderate values of $d_{0,1 / 3}$. In Figure 4 the orbital diameter is scaled by 0.75 , consistent with the $0.75 d_{0,1 / 3}$ equilibrium orbital scale ripple model as suggested by Traykovski et al. [1999]. As the energy increases in larger wave events $\left(d_{0,1 / 3}>1.2 \mathrm{~m}\right)$, the ripples do not continue to grow in wavelength. In conditions where $d_{0,1 / 3}$ is small, the Shields parameter tends to be subcritical and the ripples do not adjust. The time series data often shows that relict ripples are preserved with a fairly long wavelength after a wave event, and then rapidly adjust to a new wavelength at the beginning of the next wave event. This preservation of long wavelength relict ripples is more noticeable in the MVCO data, which had slightly coarser grain size and a larger number of wave events interspersed with periods of subcritical conditions, than in the LEO15 data.

\subsubsection{Wavelength: Orbital Diameter Phase Space and Equilibrium Models}

[16] Since ripple wavelength appears to scale with wave orbital diameter, particularly in periods of increasing wave energy at the beginning of a wave event and in moderate energy $\left(0.04<\theta_{\mathrm{w}}<0.1\right)$ conditions, it is useful to examine the ripple wavelength data as a function of orbital diameter (Figure 8). Previous studies [e.g., Wiberg and Harris [1994] have suggested that scaling both $\lambda$ and $d_{0,1 / 3}$ by $D_{50}^{-1}$ results in the collapse of the data onto a single curve spanning orbital, suborbital (a transitional state between orbital and anorbital ripples), and anorbital regimes. This plot shows that the shortest ripple wavelength for a given orbital excursion under moderate values of $d_{0,1 / 3}$ is approximately bounded by the equilibrium relation of $\lambda=0.75 d_{0,1 / 3}$ for $d_{0,1 / 3} / D_{50}$ of less than 1500 to 2000 . However, in all three data sets a large number of data points occur above and to the left (larger wavelengths and/or smaller orbital diameters) of the equilibrium ripple relationship. There are also a significant number of points to the right of the $\lambda=0.75 d_{0,1 / 3}$ equilibrium ripple relationship during energetic conditions with large wavelengths and large orbital diameters $\left(d_{0,1 / 3}>\right.$ 1500 to 2000). The points above and to the left of the curve are relict ripples left at relatively long wavelengths after a storm. These relict ripples often appear as horizontal clusters of data with constant wavelength, as the ripples remain at a long wavelength as orbital diameter decreases during the waning stages of a wave event. A typical trajectory in $\lambda-d_{0}$ space is shown by Traykovski et al. [1999] (see Figure 10 of that paper). These $\lambda-d_{0}$ space trajectories show the ripples remaining at long wavelength, or occasionally decreasing wavelength by a factor of $1 / 2$, depending on the rate of decay of the wave conditions, until the next wave event begins. At the onset of the next wave event, short wavelength ripples that are in equilibrium with the new orbital diameter forcing appear. These short wavelength ripples are often superimposed on longer wavelength ripples from the previous waves, thus creating bimodal spectra (Figures 3c, 3d, 6b, and 6d). During more energetic conditions $\left(d_{0,1 / 3}>1500\right.$ to 2000 or $\left.\theta>0.3\right)$, the ripples do not continue to grow in wavelength with orbital scaling, and reach a maximum wavelength of 0.7 to $1.2 \mathrm{~m}$. These are the points to the right of the equilibrium ripple relationship. So at large wave orbital diameters, these ripples are anorbital in the sense that they do not change wavelength in response to changes in orbital diameter. However, they have a much larger wavelength relative to grain size $(\lambda /$ $D_{50}=1000$ to 1800 , Figure 8 ) than the typical anorbital ripples found in fine sand $\left(\lambda / D_{50}=535\right.$, as suggested by Wiberg and Harris [1994]) and would thus be classified as suborbital ripples in the work of Wiberg and Harris [1994] classification scheme.

[17] In order to describe some of the variance in maximum ripple wavelength (between $\lambda / D_{50}=1000$ to 1800 or $\lambda=0.70$ to $1.5 \mathrm{~m}$ ), Smith and Wiberg [2006] suggested a maximum orbital ripple wavelength that is determined by a suspension threshold. Their threshold for suspension determines the maximum wavelength of the suborbital ripples by calculating the orbital diameter at the time that the ratio of the grain roughness wave shear velocity $\left(u^{*}=\sqrt{\tau_{\mathrm{w}}} / \rho\right)$ to the particle settling velocity $\left(w_{\mathrm{s}}\right)$ is approximately one. For conditions with $u^{*}<w_{\mathrm{s}}$, the ripples obey the Wiberg and 

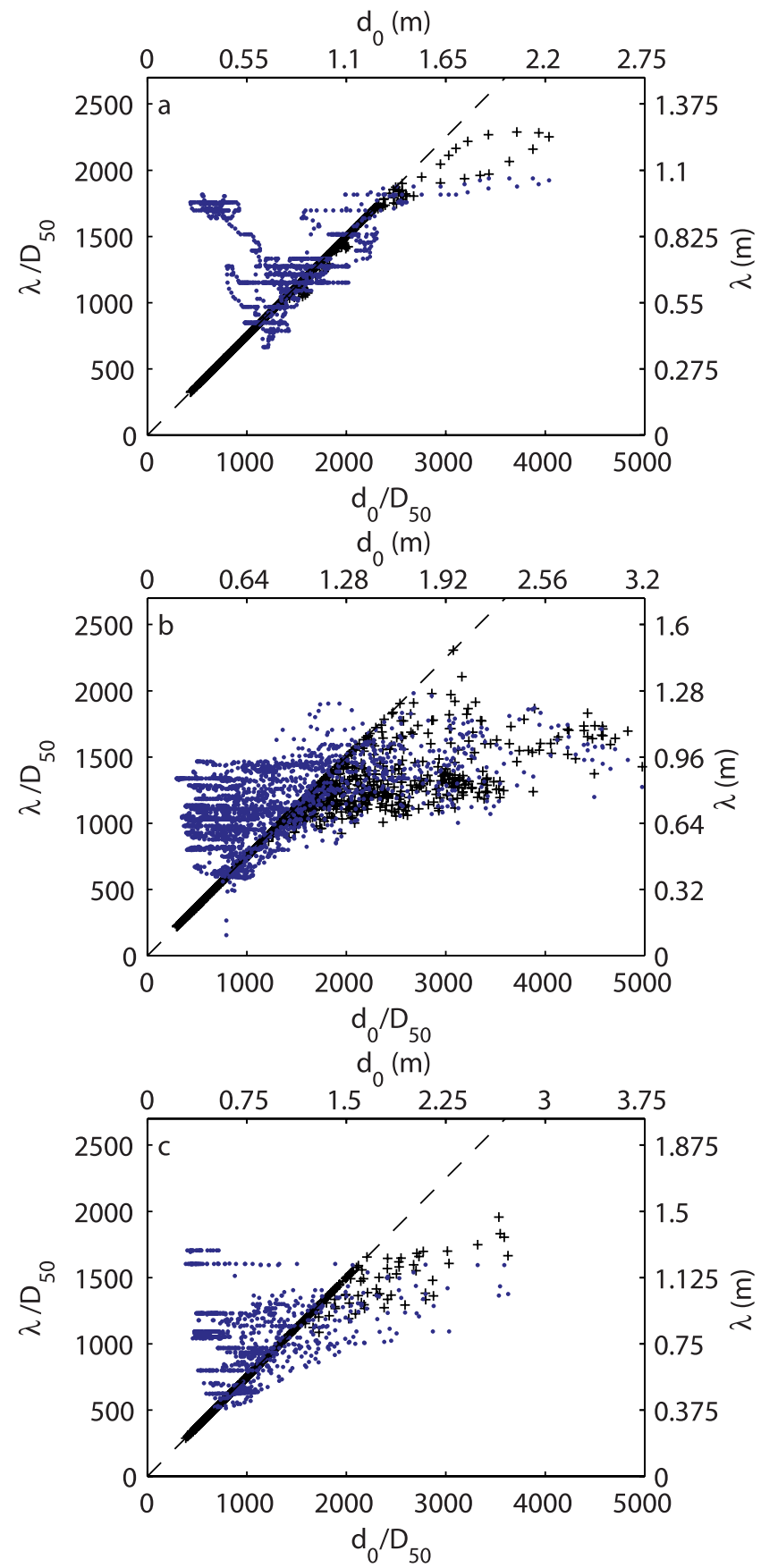

Figure 8. Ripple observations (blue dots) and equilibrium model results (black + s) for (a) LEO15, (b) MVCO02, and (c) MVCO05. The black dashed line represents the equilibrium relation of $\lambda=0.75 d_{0,1 / 3}$ without the wave period dependent maximum ripple wavelength cut-off that is seen as the black circles depart from the dashed line. The lower $x$ axis and left $y$ axis are normalized by median grain diameter, while the upper $x$ axis and right $y$ axis are not normalized, with units of meters.

Harris [1994] equilibrium ripple relation of $\lambda=0.62 d_{0,1 / 3}$, whereas for conditions with $u^{*}>w_{\mathrm{s}}$, the ripple wavelength is equal to 0.62 times the wave orbital diameter (calculated by the forcing wave period and the velocity associated with $u^{*}=$ $w_{\mathrm{s}}$ ). This criterion makes the maximum ripple wavelength a function of both wave orbital diameter and wave period. For longer wave periods, larger maximum wavelengths are predicted, as the velocities associated with longer periods are lower for the same orbital diameter. This threshold (based on shear velocity calculated from grain roughness is over simplified), as the turbulence calculation that determines the transition to suspension is based on a friction coefficient. Friction coefficients poorly describe flow over orbital scale bed forms that typically have heights larger than the wave boundary layer thickness. However, examining the data shows that a suspension threshold of approximately one works fairly well. For the purposes of this paper, a velocity threshold of $\left(u_{\mathrm{b}, 1 / 3} / w_{\mathrm{s}}=4.2\right)$ was used rather than a shear velocity threshold. Here the settling velocity is calculated using the Gibbs et al. [1971] formula. The constant of 4.2 was determined by a fit to the observations, and it is roughly consistent with a typical ripple slope of 0.2 to 0.3 (i.e., $1 / 4.2=$ 0.23 ). This relationship to the ripple slope is based on the concept that if settling velocity is greater than the ripple slope times the horizontal velocity, the particles will settle on the same ripple, whereas if settling velocity is greater than $u_{\mathrm{b}, 1 / 3}$ the particles will be advected onto the next ripple and the transition to more complex morphologies may occur. This approach is also overly simplistic given the complexity of turbulent flow over orbital scale ripples, but results in a fit over range of wave velocities and periods that is as good as the shear velocity approach and the velocity threshold approach is slightly simpler to apply.

[18] On the basis of the velocity threshold for maximum wavelength and the equilibrium relation of $\lambda=0.75 d_{0,1 / 3}$ defined by Traykovski et al. [1999], an equilibrium model of

$$
\begin{array}{cc}
\lambda_{\text {eq }}=0.75 d_{0,1 / 3}=1.5 u_{\mathrm{b}, 1 / 3} / \omega_{\mathrm{r}} & u_{\mathrm{b}, 1 / 3} \leq 4.2 w_{\mathrm{s}} \\
\lambda_{\mathrm{eq}}=1.5\left(4.2 w_{\mathrm{s}}\right) / \omega_{\mathrm{r}} & u_{\mathrm{b}, 1 / 3}>4.2 w_{\mathrm{s}}
\end{array}
$$

is used here for the ripples in coarse sand. Some of the variance in ripple wavelength at the highest wave orbital diameters $\left(d_{0,1 / 3}>2 \mathrm{~m}\right)$ may also be due to measurement uncertainties, since ripples evolve into a more complex three-dimensional ripple morphology as discussed in the next section.

2.2.3. Morphology of Ripples in Energetic Conditions $\left(\theta>0.3\right.$ or $\left.d_{0,1 / 3}>1.5 \mathrm{~m}\right)$

[19] These data sets with orbital scale ripples show that the ripples continue to become longer crested and more regular (Figure 9) as wave energy increases up to a Shields parameter of approximately 0.2 , if the waves are not changing direction or changing orbital diameter too rapidly. In excess of a Shields number of 0.2 to 0.3 the bed forms become highly three-dimensional, occasionally showing lunate characteristics (Figure 9b) similar to lunate megaripples seen near the surf zone [Ngusaru and Hay, 2004], or showing characteristics of large scale cross ripples [Hay and Mudge, 2005]. Height estimates of the complex bed forms show crest to trough heights of 0.2 to $0.3 \mathrm{~m}$. On the basis of the Shields parameters, this complex three-dimensional morphology may be due to transition from bed load dominated to suspended load-dominated conditions. Up to the maximum observed wave averaged Shields number of approximately 0.5 , the bed forms in coarse sand show no indication of approaching a flat bed or reducing steepness, as has been observed in finer sands and is included in many equilibrium ripple models. As the Shields number 

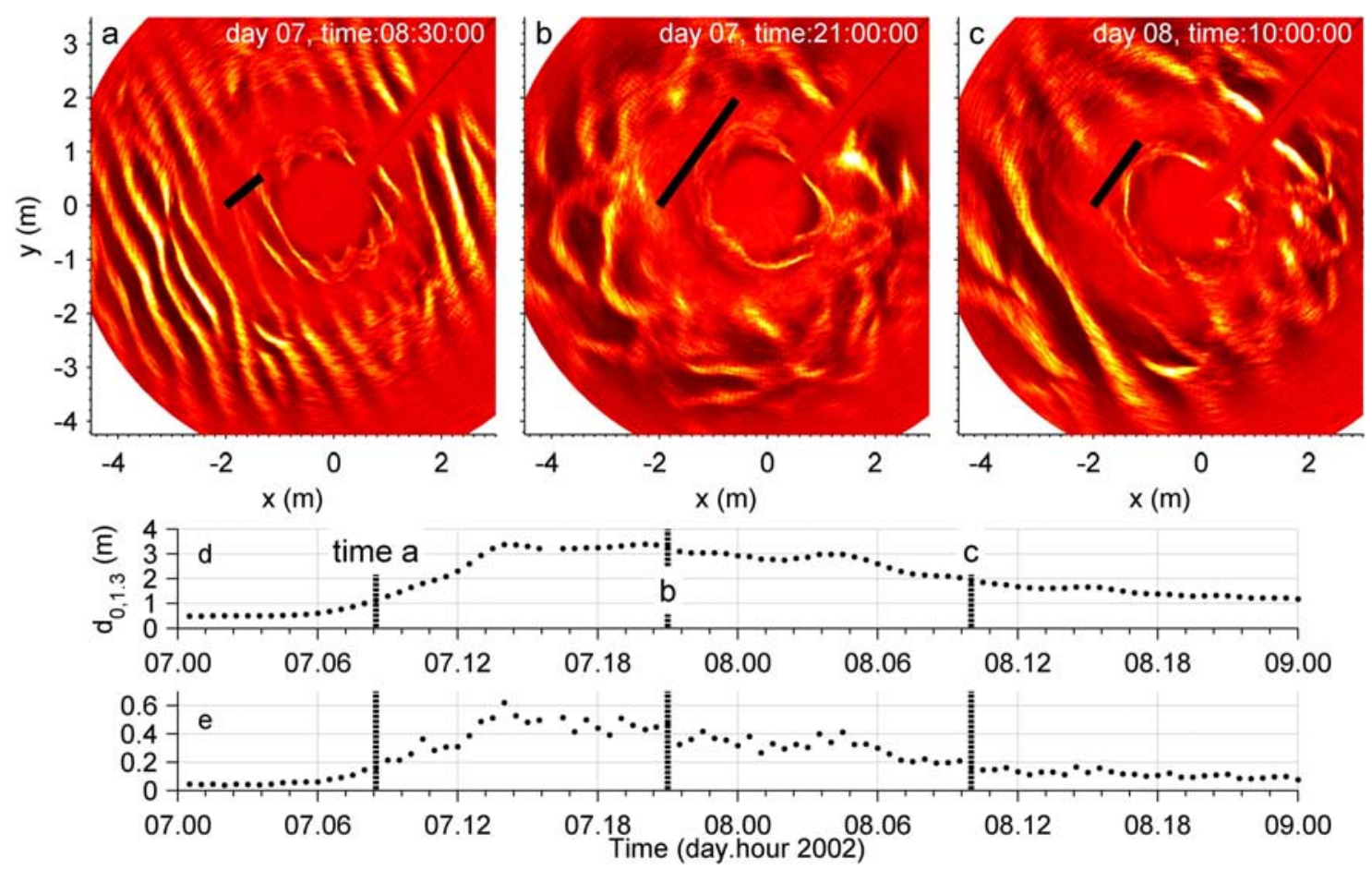

Figure 9. MVCO 02 data showing the transition from (a) long crested ripples at the beginning of a wave event, with Shields number around 0.2 , to (b) complex three-dimensional irregular ripples with Shields number around 0.4 to 0.6 , and then back to (c) long crested ripples with Shields number around 0.2 . Time series of (d) wave orbital diameter $\left(d_{0,1 / 3}\right)$ and (e) wave Shields parameter are marked with dashed lines correspond to the time Figures $9 \mathrm{a}, 9 \mathrm{~b}$, and $9 \mathrm{c}$ were acquired.

approaches 0.5 , many of the bed forms are partially hidden from view in sonar imagery due to clouds of suspended sand attenuating the acoustic energy. However, the brief glimpses of the ripples in between clouds of suspended sediment do not show flattening on the ripples.

\section{Time-Dependent Modeling}

\subsection{Formulation of a Model for the Temporal Evolution of Ripples}

[20] In order to quantify the relation between forcing hydrodynamics and ripple morphology when the ripples are not necessarily in equilibrium with the hydrodynamic forcing, a time-dependent model is required. On the basis of the scour literature [Whitehouse, 1998] and the sediment continuity equation, a time-dependent model can be derived as follows. The flux convergence term $(\mathrm{d} Q / \mathrm{d} x)$ in the sediment continuity equation is scaled by a heuristic "departure from equilibrium" factor $\left(\left(\eta_{\mathrm{eq}}(k)-\eta(k)\right) /\right.$ $\eta_{\mathrm{s}}(k)$ ), based on the concept that when ripples are far from equilibrium, the transport convergence required to drive the ripples toward an equilibrium state will be maximized, whereas when the ripples are close to equilibrium transport convergence will be minimized.

$$
(1-\phi) \frac{d \eta(k)}{d t}=\frac{d Q}{d x} \frac{\left(\eta_{\mathrm{eq}}(k)-\eta(k)\right)}{\eta_{\mathrm{s}}(k)}
$$

This equation models the temporal evolution of the ripple spectral components $(\eta(k))$ as a relaxation process, with the assumption that each wave number component of ripple spectra evolves independently. Comparison with data in a subsequent section will examine the validity of this approach. The term $(1-\phi$, where $\phi$ is set to 0.35$)$ accounts for the porosity of sand in the ripples. The flux convergence term is treated as a scaling term based on the approximation that convergence goes to zero at the ripple trough and is maximized at the crest.

$$
\frac{d Q}{d x}=\frac{Q}{\lambda_{\mathrm{s}} / 2}
$$

Here the bed load flux rate is calculated using a bed load formula of Meyer-Peter and Muller [1948]) whereby

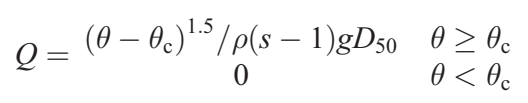

On the basis of the observations discussed by Traykovski et al. [1999], it is assumed that the ripple evolution processes are dominated by bed load flux. The use of this steady flow bed load formula under oscillatory forcing is also discussed by Hsu and Hanes [2004] and Hsu and Raubenheimer [2006]. If suspended sediment transport also contributes to ripple formation processes, this formulation involving bed load flux only may over estimate the adjustment timescale. However, during the energetic periods where suspended load is likely to be important the adjustment timescale tends to be much shorter than the timescale of the variability of the wave forcing, so the omission of a suspended load contribution 


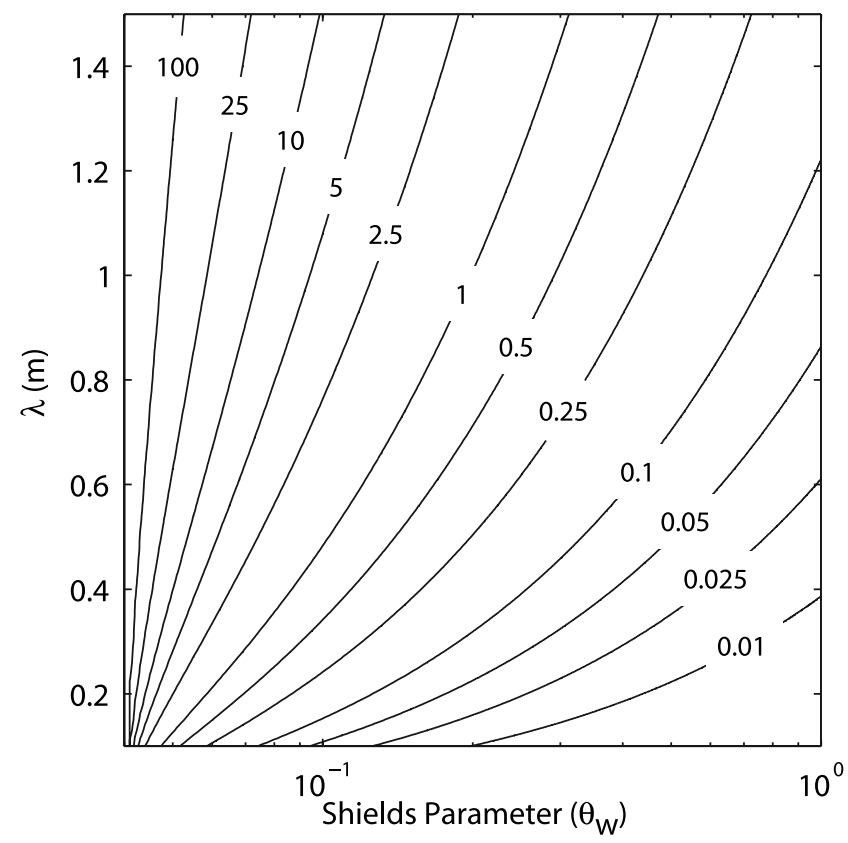

Figure 10. Contours of ripple adjustment timescale (with units of hours) as a function of ripple wavelength and Shields parameter.

should not be significant. The wavelength in equation (7) is also a function of wave number $(\lambda=2 \pi / k)$. Here the Shields parameter $(\theta)$ is calculated from wave stress only [equation (3)]. Thus equation (6) becomes

$$
\frac{d \eta(k)}{d t}=\frac{\eta_{e q}(k)-\eta(k)}{T(k)} .
$$

The adjustment timescale for each wave number $(T(k)=$ $\left.(1-\phi) \eta_{\mathrm{s}} \lambda_{\mathrm{s}} / 2 Q=(1-\phi) 0.16(2 \pi / k)^{2} / 2 Q\right)$ is equal to the cross-sectional area of each ripple spectral component divided by the bed load transport rate. Laboratory studies for the temporal adjustment of ripples have generally considered the timescale to be a function of sediment transport rate and not the ripple cross-sectional area [Smith and Sleath, 2005; Testik et al., 2005]. The ripple shape is approximated by a triangle for this calculation, and a steepness relation of $\eta_{\mathrm{s}}=0.16 \lambda_{\mathrm{s}}$ has been assumed. The variables $\eta_{\mathrm{s}}$ and $\lambda_{\mathrm{s}}$ are denoted with the subscript "s" since they are scaling parameters applied to the equilibrium ripple spectra that are used to force the model. The variables $\eta_{\mathrm{s}}$ and $\lambda_{\mathrm{s}}$ depend on only wave number and are constant in time, unlike the spectral amplitudes $(\eta)$, the equilibrium spectral amplitudes $\left(\eta_{\mathrm{eq}}\right)$, and the predicted steepness, which vary in time in response to forcing conditions. This timescale allows large ripples under low stresses to adjust slowly while allowing small ripples under high stresses to adjust quickly (Figure 10). Under the most energetic conditions in the observations $\left(\theta_{\mathrm{w}} \sim\right.$ $0.5)$ the adjustment timescale becomes a few minutes or less and thus on the order of the wave group timescale.

[21] In response to a step change in forcing conditions, the solution to equation (9) is an exponential adjustment: $\eta(k)=\eta_{\mathrm{eq}}(k)\left(1-e^{-t / T(k)}\right)$. This formulation has been used extensively in the scour literature, and various approaches to time stepping the exponential solution have been developed [Sumer and Fredsøe, 2002; Trembanis et al., 2007; Whitehouse, 1998]. The literature on ripples generated in laboratory flumes also examines this type of exponential decay [Smith and Sleath, 2005; Testik et al., 2005; Voropayev et al., 1999; Voropayev et al., 2003]. However, here we discretize and time-step the differential equation [equation (9)] directly, as this allows the most accuracy in following changing input conditions and avoids awkward approaches to using exponential decay solution with variable forcing and temporal adjustment scales. The input parameters into the model are $\theta, \theta_{\mathrm{c}}, D_{50}$, and $\eta_{\mathrm{eq}}(k)$. The Shields parameter is calculated from the wave parameters as described previously. The critical Shields parameter $\left(\theta_{c}\right)$ is assigned a value of 0.04 for the sand sizes in these experiments. To calculate $\eta_{\mathrm{eq}}$ any two of the three following parameters are required: wave velocity $\left(u_{\mathrm{br}, 1 / 3}\right)$, wave frequency $\left(\omega_{\mathrm{r}}\right)$, and orbital diameter $\left(d_{0,1 / 3}\right)$. Thus an alternative set of complete input parameters to the model is $u_{\mathrm{br}, 1 / 3}, d_{0,1 / 3}, \theta_{\mathrm{c}}$, and $D_{50}$.

[22] The equilibrium ripple spectra are modeled by a Gaussian distribution:

$$
\eta_{e q}(k)=\frac{0.25 \eta_{e q, p}}{\sqrt{\sigma(2 \pi)^{1 / 2}}} e^{-\left(k-k_{\mathrm{p}}\right)^{2} / 4 \sigma^{2}}
$$

with the peak equilibrium wave number $\left(k_{\mathrm{p}}=2 \pi / \lambda_{\text {eq }}\right)$ calculated from the peak equilibrium wavelength as determined by equation (5) and amplitude $\left(\eta_{\text {eq,p }}\right)$ calculated from an equilibrium steepness relation $\left(\eta_{\mathrm{eq}, \mathrm{p}} / \lambda_{\mathrm{eq}}=0.16\right)$. The bandwidth $(\sigma)$ was set to $0.1 \mathrm{rad} / \mathrm{m}$ based on observations of ripple spectra. Sensitivity tests show that the model output for wavelength (estimated as the peak of the spectra) was not very sensitive to the choice of bandwidth. The factor of 0.25 arises since the ripple height is calculated from the spectrum in a manner similar to the calculation of significant wave height [equation (4)]. The actual observed ripple profiles are not sinusoidal but typically have broader troughs and sharper crests than a sinusoid. Thus the observed spectra have low amplitude harmonics which are not included in this spectral model for the sake of simplicity.

[23] In order to compare the model to data, the model was run two ways: (1) as described above (henceforth called the variable timescale model) and (2) in a "binary timescale" mode. In the binary timescale mode, the timescale $T(k)$ is set to a small value when $\theta>\theta_{\mathrm{c}}$ and a large value when $\theta<\theta_{\mathrm{c}}$. The small and large values approximate 0 and $\infty$, but finite values are used for numerical stability. This ensures that when sediment is in motion, the modeled ripples are always in equilibrium with the forcing, and are preserved at the state consistent with $\theta=\theta_{\mathrm{c}}$ when the stress becomes subcritical. For the binary timescale model, the wavelength at preservation is then an exact function of orbital diameter at the time when the stress equals the critical stress, while for the full model it depends on both conditions at $\theta=\theta_{\mathrm{c}}$ and on the time history prior to $\theta=\theta_{\mathrm{c}}$. The motivation for examining the binary approach is that some sediment transport models use this in the implementation of the ripple calculation subroutine (for example, ROMS sediment transport [Warner et al., 2007]). Other sediment transport 

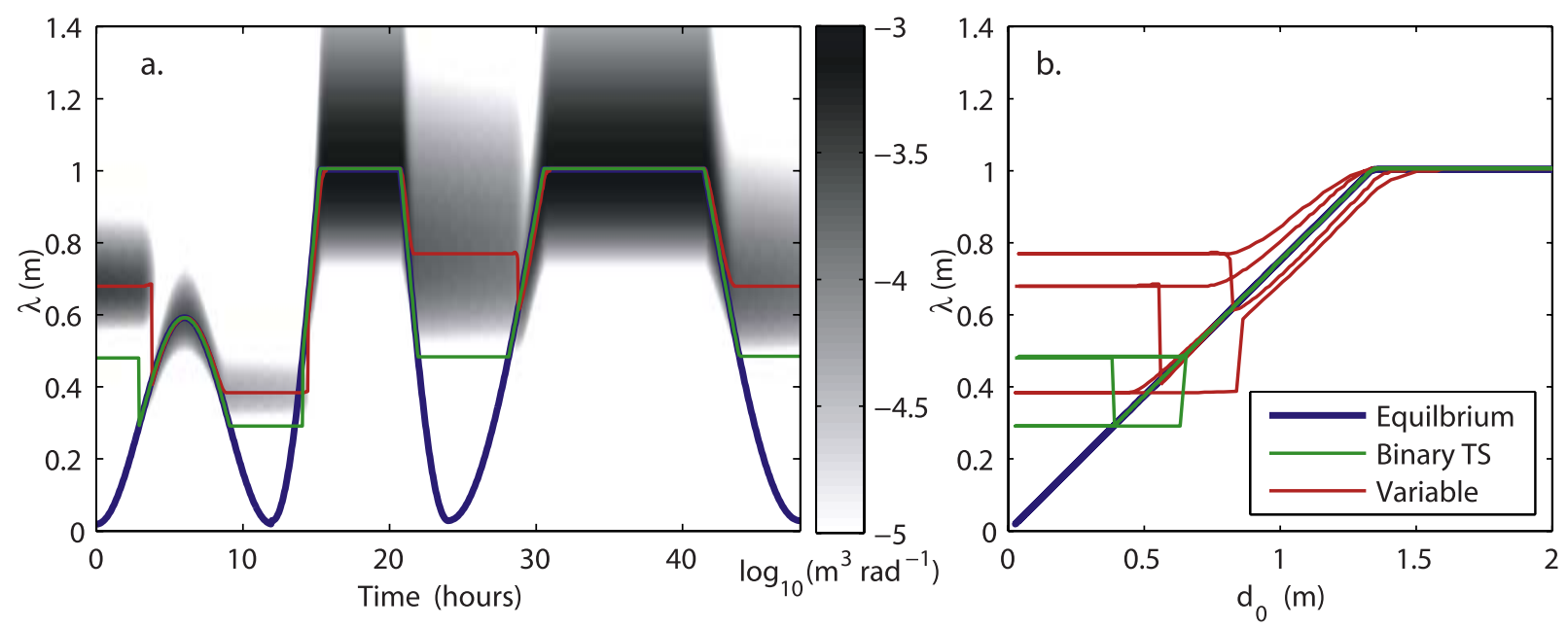

Figure 11. Simulated data model runs. The simulated data consists a wave event with $u_{\mathrm{b}, 1 / 3}=0.30 \mathrm{~m} / \mathrm{s}$, period $=8 \mathrm{~s}$, followed by two additional wave events with $u_{\mathrm{b}, 1 / 3}=0.50 \mathrm{~m} / \mathrm{s}$, period $=12 \mathrm{~s}$. In the two latter wave events, the first is 12 hours in duration and the second is 24 hours in duration. (a) Time series of predicted spectra (gray scale intensity) and wavelength estimates from the equilibrium model (blue), the binary timescale model (green), and the variable timescale model (red). (b) Results as a plotted as a function of the parameters $\lambda$ and $d_{0}$.

models allow ripples and the associated roughness to evolve in equilibrium with wave forcing during subcritical bed stress conditions (for example, Delft3d [Lesser et al., 2000] and [Styles and Glenn, 2002]) or set the roughness to some background level during periods of low stress [Harris and Wiberg, 2001; Li and Amos, 2001]).

\subsection{Simulated Input Model Runs}

[24] To illustrate the difference between the equilibrium model, the binary timescale model and the variable timescale model, the models were run by simulating three wave events. The first event had peak wave velocities of $0.3 \mathrm{~m} / \mathrm{s}$ (period $=8 \mathrm{~s}$ ) and the second two events had peak velocities of $0.5 \mathrm{~m} / \mathrm{s}$ (period $=12 \mathrm{~s}$, Figure 11a). The first and second wave events were both 12 hours long while the third one was 24 hours long. The model run was initialized with relict ripples with wavelengths of $0.68 \mathrm{~m}$ for the variable timescale model and $0.48 \mathrm{~m}$ for the binary timescale model, consistent with the final conditions. At 3.0 hours into the first wave event, the binary timescale model immediately adjusted to a new wavelength of $0.3 \mathrm{~m}$ as critical conditions were exceeded. For the next 0.8 hours the variable timescale model predicted a bimodal spectrum, with a peak at $0.75 \mathrm{~m}$ and a shorter wavelength peak that followed the increasing equilibrium wavelength. The binary timescale model can only predict unimodal spectra with a peak at the equilibrium wavelength, or in the case where the Shields number decreased below critical, at the last equilibrium value. During the portion of the wave events with $\theta>\theta_{c}$, both models follow the equilibrium solution, with a very slight delay visible in the variable timescale model solution. These slight delays appear as offsets from the equilibrium relation in $\lambda-d_{0}$ parameter space (Figure 11b). The offsets seen in the simulated data, due to temporal delays in ripple adjustment, may account for some of the spread of the observed data about the equilibrium relation during moderate conditions.
[25] The difference between the binary and the variable timescale model is also seen by comparing the second and third events. The binary timescale model predicts equal wavelengths after both events, while the variable timescale model predicts a shorter wavelength after the third event due to the longer time over which the wave orbital diameter changes ( 24 hours for the third event versus 12 hours for the second event). Since the wave velocity and period was the same in the second and third wave events the adjustment timescale $(T)$ was the same for both events, but the longer duration of the third storm allowed the ripples stay in phase with the forcing. Thus the 24-hour wave event results in shorter wavelength relict ripples with the variable timescale model as compared to the binary timescale model or equilibrium model.

[26] After all three wave events, the variable timescale model predicts longer relict ripples preserved than does the binary timescale model due to the model dynamics, whereby only the shortest wavelength components adjust rapidly at low stresses. Consistent with the observed data, both the binary timescale and the variable timescale model simulated input results show horizontal lines to the left and above the equilibrium relation in $\lambda-d_{0}$ parameter space, as relict ripples are preserved after the wave events. The models also show horizontal lines to the right of the equilibrium curve at low wavelengths because the second wave event has a longer period than the first wave event thus the bottom stress exceeds critical stress at a longer orbital diameter than in the first wave event (around hour 15). Consistent with the observed data, the model shows a pattern whereby the ripple wavelength rapidly adjusts at the beginning of a wave event (visible in the first and third wave events for the variable timescale model) and then grows with orbital scaling.

\subsection{Model-Data Comparison}

[27] Both the binary timescale model and the variable timescale model were run with hydrodynamic and sediment 

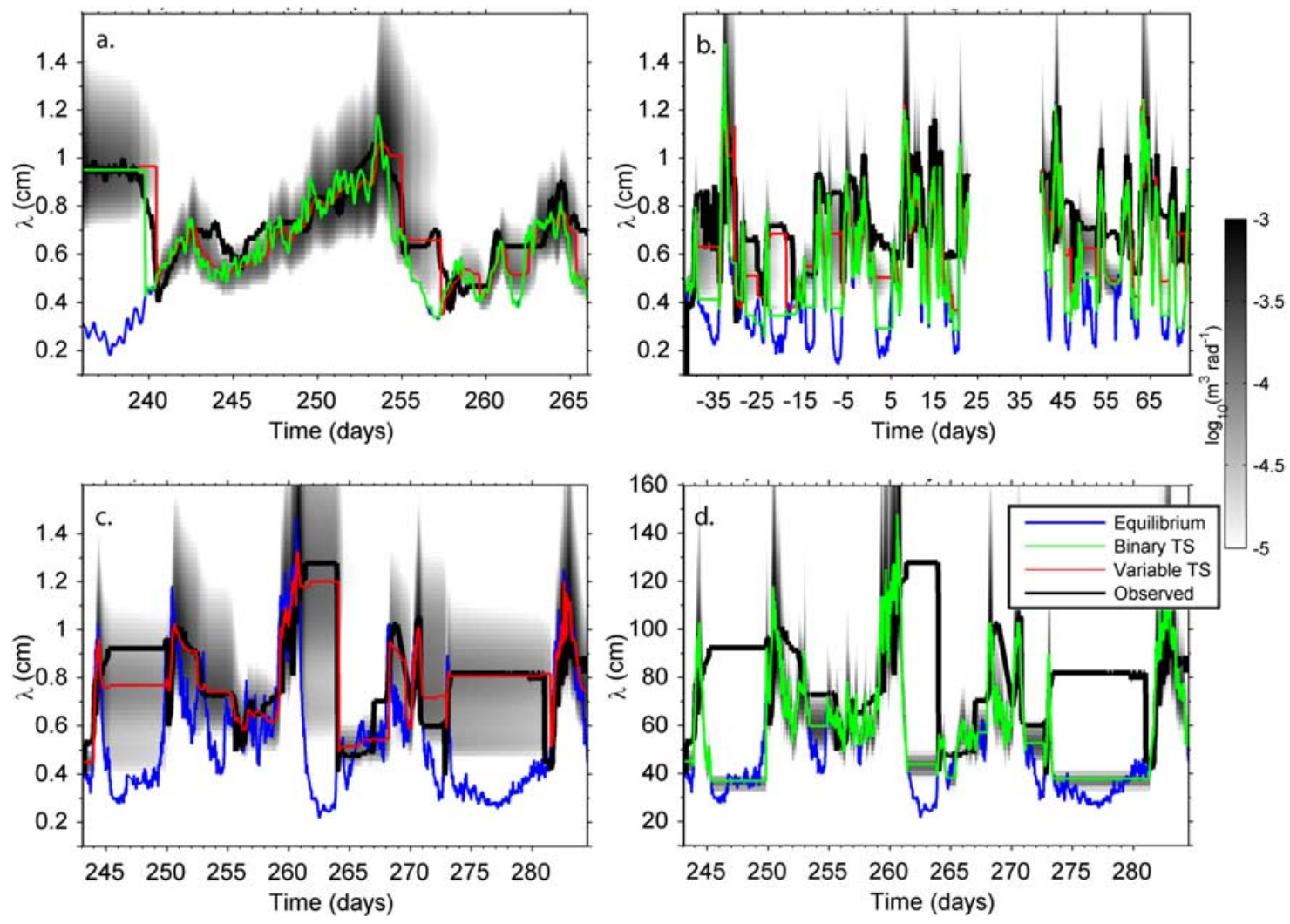

Figure 12. Time series of model predicted spectra (gray scale intensity), model predicted wavelength (colored lines), and observed wavelength (black lines) for (a) LEO, (b) MVCO02, (c) MVCO05 05 variable timescale model, and (d) MVCO 05 binary timescale model.

input parameters from the three data sets. The model runs were initialized with ripple wavelengths from the observations and equilibrium ripple heights consistent with the observed wavelength at the first time step. In order to optimize the models' ability to fit the observed wavelength data, a single tuning parameter was introduced by scaling the timescale $(T)$ by a constant $\left(\alpha_{\mathrm{t}}\right)$. The same constant $\left(\alpha_{\mathrm{t}}=\right.$ 3.7) was used for all model runs. This tuning accounts for both uncertainties in the stress estimates and uncertainties in the heuristic approach to scaling transport convergence in equation (7), and is surprisingly close to unity given the level of approximation in the approach. The stress estimate is based on flow over a flat bottom with a roughness defined by the grain diameter, and is not based on flow over a rippled seafloor. Thus the transport convergence scaling and the timescale are relative measures of ripple adjustment time and require scaling to best fit the data. Alternate approaches, such as using a power law dependence for the timescale, have been employed in the scour literature [Whitehouse, 1998], but a linear scaling is used here for simplicity.

[28] A second modification to the model was performed to account for the role of mean current induced stress in the degradation of wave-formed orbital scale ripples. The observations show events where mean currents rapidly (within a single tidal phase) degrade a wave formed ripple field that otherwise may have been preserved with relatively long wavelength relict ripples. For instance during yearday 257 in the LEO15 data set, the large ripples are completely flattened by the combination of waves and mean currents (this is described in more detail by Traykovski et al. [1999]. In order to account for this phenomenon during periods when a particular ripple spectral component is decreasing, the Shields parameter in equation (8) is replaced by $\theta=\theta_{\mathrm{w}}+$ $\theta_{\text {cur }}$, where the current stress is calculated from a drag coefficient as described by Traykovski et al. [1999]. These modifications to the model were applied to both the variable timescale model and the binary timescale model.

[29] The predicted ripple wavelength is estimated from ripple elevation spectra by finding the peak of the spectra in a manner similar to the technique applied to the measured spectra. The predicted ripple height is found by integrating the spectra in a similar manner to the ripple height technique used with the observations [equation (4)].

\subsubsection{Time Series Results}

[30] Time series of observed ripple wavelength and model output for the three model options (equilibrium, binary timescale, variable timescale) show increasing ability to match observations as model complexity is increased. The LEO15 model runs show the spectral energy shifting from the long wavelength ripples that were present at deployment and used as initial conditions for the model runs to the shorter wavelength ripples created from the first wave event (Figure 12a). The wavelength estimated from the peak of the variable timescale spectra (red lines in Figure 12) slightly lags the observations, but a wavelength estimate based on the spectral mean of the model output (not shown) does not show this lag. This different performance of the mean and peak wavelength parameter estimator is due to the 
model predicting a bimodal spectrum during the transition, consistent with observations. After the peak of the first wave event, the observations show a period of 1.5 days where the ripples remain at their peak wavelength before decreasing. While the peak wavelength estimates from either the variable timescale or binary timescale model do not show this delay, the spectra from the variable timescale model does show a significant amount of long wavelength energy which persists for the same 1.5 days. As wave orbital diameter begins to increase during the vent from day 245 to 253 , the wavelength predicted by the variable timescale model increases more smoothly, as some of the high frequency fluctuations in wave orbital diameter forcing (and binary timescale model output) are effectively filtered out by the finite temporal adjustment timescale. The binary and equilibrium models do not have this filtering. For this data set, the binary model exactly matches the equilibrium forcing, since the Shields parameter is above the critical value except for the initial four days. The observations show less high-frequency variability than the wave orbital diameter forcing, but are not exactly matched by the variable timescale model. After the peak of this second wave event (day 253.5), the observed wavelength lags the decreasing wave orbital diameter by approximately 1 day. While significant amounts of predicted long wavelength spectral variance remains for several days after the peak of the wave event, inconsistent with data (Figure 12a), the peak wavelength parameter estimate from the model closely matches the observations. As the waves are decreasing in wave orbital diameter, there is a period of one day (254-255) during which the wave orbital diameter remains constant. This allows the formation of $0.6-\mathrm{m}$ wavelength ripples, which remain for the next 3 days $(255-258)$. This ripple behavior is successfully predicted by the variable timescale model, while not captured by the binary timescale model. On day 257, strong mean currents combined with waves allowed the ripple adjustment timescale to become short enough so that the ripples are flattened. Correctly modeling this behavior required incorporation of the combined wave and mean current stress as described in section 3.3.

[31] With the MVCO02 data set, the variable timescale model has an increased ability to predict long wavelength ripples preserved after wave events compared the binary timescale model (Figure 12b). The observations typically show relict ripple wavelengths of 0.6 to $0.8 \mathrm{~m}$ after wave events. The binary timescale model incorrectly predicts wavelengths of 0.3 to $0.5 \mathrm{~m}$ after most wave events due to the lack of a temporal delay in weak forcing conditions. The relatively low variability (between 0.3 and $0.5 \mathrm{~m}$ ) is due to strong correlation of wave orbital diameter and Shields parameter, which is a result of the relatively small range of wave periods $(8-10 \mathrm{~s})$ at the time that the Shields parameter decreases below the critical level. The variable timescale model has a slow adjustment timescale for large ripples, and is able to correctly predict wavelengths of 0.6 to $0.8 \mathrm{~m}$ after most wave events.

[32] The MVCO05 data set also shows long wavelength relict ripples that are correctly modeled by the variable timescale approach, and incorrectly modeled by the binary timescale approach. For this data set, measurements of the ripple elevation spectra are available, and these can be compared to the model spectral output. The ripple elevation measurements show a bimodal spectrum after the first wave event (Figure 12c, day 250, and Figures $4 \mathrm{c}$ and $4 \mathrm{~d}$ ). The variable timescale model is able to predict this occurrence of bimodal ripple spectra, although it slightly underestimates the wavelength in both peaks. As described in section 3.2 the binary timescale model is unable to predict bimodal spectra. An additional occurrence of bimodal spectra is visible in the data and the model output after the wave event on day 260-264. In the events where unimodal spectra are preserved (for example, after day 252) the variable timescale model predicts broad bandwidth spectra, consistent with the observations, compared to the narrow bandwidth spectra of the binary timescale model. This spectral spreading is due to the long adjustment timescale for large ripples. Longer wavelength ripples also appear to have broader spectra in the figures since the calculations are performed with spectral components with equally spaced wave numbers and the results are displayed versus wavelength, which broadens low wave number spectra and compresses high wave number spectra.

[33] One feature of the observations that is not well captured by the any of the models is the significant decrease in wavelength at the beginning of wave events as the ripples adjust to new short orbital diameter forcing conditions. Before the wave events on yeardays $250,262,277$, and 282 , there is a rapid decrease in wavelength as small ripples appear due to the arrival of the next waves. The model is capable of predicting these decreases in wavelength (see simulated data section) and does predict a slight decrease in wavelength before the wave event on day 282 , but it does not predict as dramatic a decrease as the data shows. This would suggest that there may be some asymmetry to the ripple adjustment timescale from before a wave event to after a wave event, or that the ripple timescale does not vary linearly with ripple size and should be parameterized by a power law dependence, as used by some of the scour models in the literature [Whitehouse, 1998].

\subsubsection{Wavelength: Orbital Diameter Phase Space Time-Dependent Modeling Results}

[34] Examining the model results in wavelength diameter $\left(\lambda-d_{0}\right)$ phase space reveals the differences in the models' abilities to capture nonequilibrium ripples (Figure 13, left panels). As seen in the observations, relict ripples left after wave events occupy the space above and to the left of the equilibrium orbital scaling relation, and nonequilibrium behavior during the course of a wave event results in spreading of the data points both to the left and to the right of the equilibrium curve. Because of this difference between the equilibrium ripples and actual ripple behavior, plotting the equilibrium model predictions against the measured wavelengths (Figure 13, blue circles in right panels) results in a wide spread about the one to one relation. To quantify this error the residual variance is scaled by the variance in the observations:

$$
S E V=\frac{\sum\left(\lambda_{o b s}-\lambda_{p r e d}\right)^{2}}{\sum\left(\lambda_{o b s}-\overline{\lambda_{o b s}}\right)^{2}}
$$

Here $S E V$ is an abbreviation for standardized error variance. The equilibrium model has high values of SEV for all three data sets $(3.2,3.1$, and 4.0 for LEO, MVCO02 and 

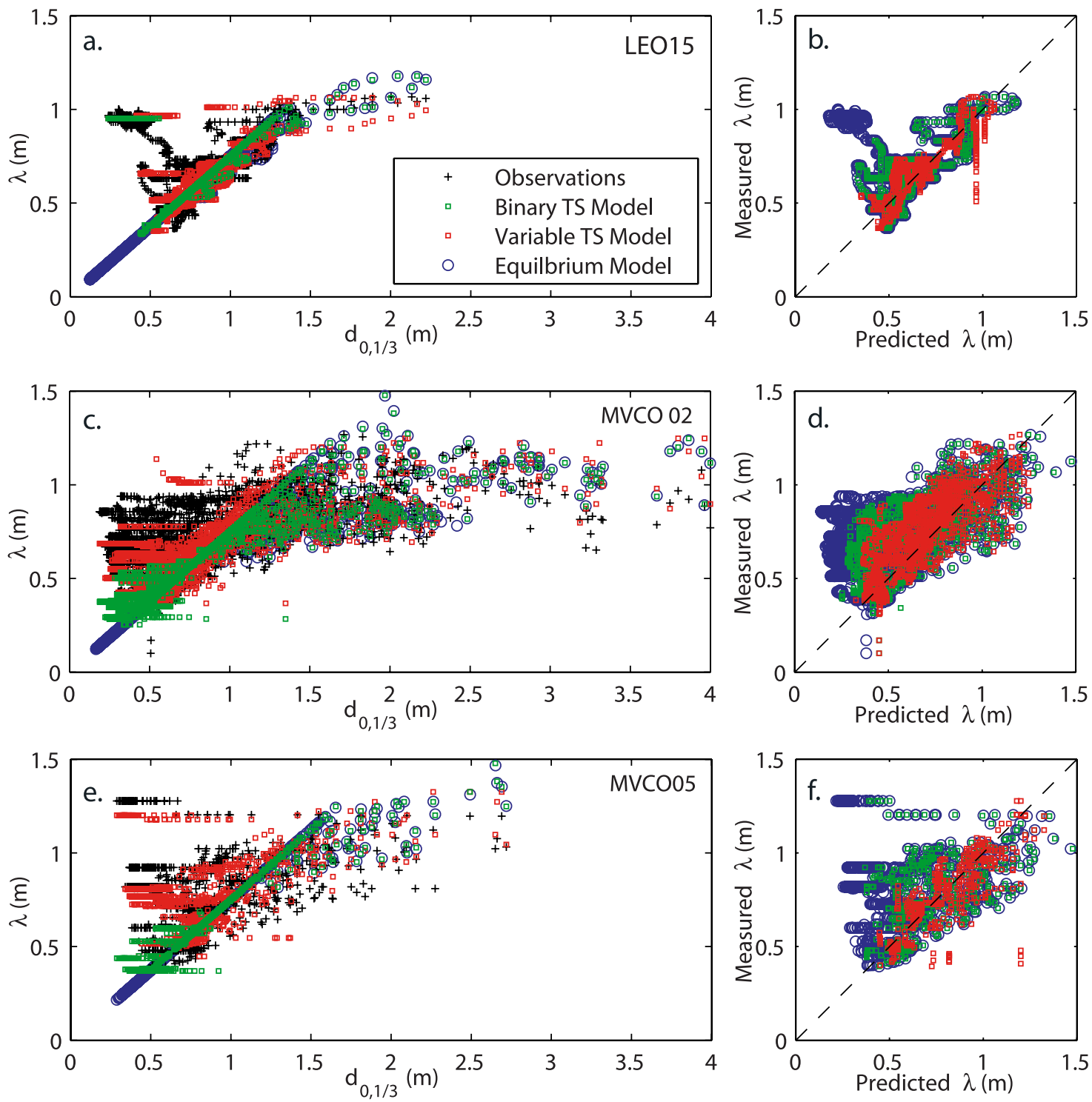

Figure 13. Model and data comparison. (a, c, and e) Left side panels show observed wavelength and model estimates of wavelength from the three modeling approaches as a function of the parameter $d_{0,1 / 3}$ and (b, $d$, and f) right side panels show observed wavelength versus model predicted wavelength for (a and b) LEO15, (c and d) MVCO02, and (e and f) MVCO05.

MVCO05, respectively, Table 1). These values of greater than one indicate that for both equilibrium and relict conditions, the mean of the observed wavelength $(0.71$, 0.72 , and $0.80 \mathrm{~m}$ ) would be a better ripple wavelength predictor than using the equilibrium relation.

[35] The binary timescale model predicts model output points on the $\lambda=0.75 d_{0,1 / 3}$ line except at low orbital diameters, when the Shields numbers are subcritical (Figure 13, green dots in left panels) and at high orbital diameter when the equilibrium relation predicts suborbital ripples. With the exception of the LEO15 data set, where relict ripples existed as an initial condition, the relict ripples predicted by the binary timescale model have wavelengths of 0.3 to $0.6 \mathrm{~m}$. While the data does show some relict ripples at these wavelengths, there are a large number of relict ripple data points at longer wavelengths. Thus the binary timescale model is only a significant improvement over the equilibrium model for the LEO15 data ( $S E V$ reduced from 3.2 to 0.47 ), in which most of the data points are close to equilibrium since the measurements occurred mostly in active conditions. For the MVCO data sets the binary timescale model still has $S E V$ values over one, indicating that the mean of the observations is still a better

Table 1. Standardized Error Variances (SEV) for the Three Different Modeling Approaches and Three Data Sets, Calculated Using Equation $11^{\mathrm{a}}$

\begin{tabular}{llll}
\hline & \multicolumn{1}{c}{ LEO } & MVCO02 & MVCO05 \\
\hline Equilibrium Model & 3.2 & 3.1 & 4.0 \\
Binary Time Scale & $0.45(15 \%)$ & $2.2(72 \%)$ & $3.3(82 \%)$ \\
Variable Time Scale & $0.25(8 \%)$ & $0.78(25 \%)$ & $0.32(8 \%)$ \\
\hline
\end{tabular}

${ }^{\text {a }}$ The numbers in parentheses are the percentage of the equilibrium SEV for the alternate modeling approaches. 

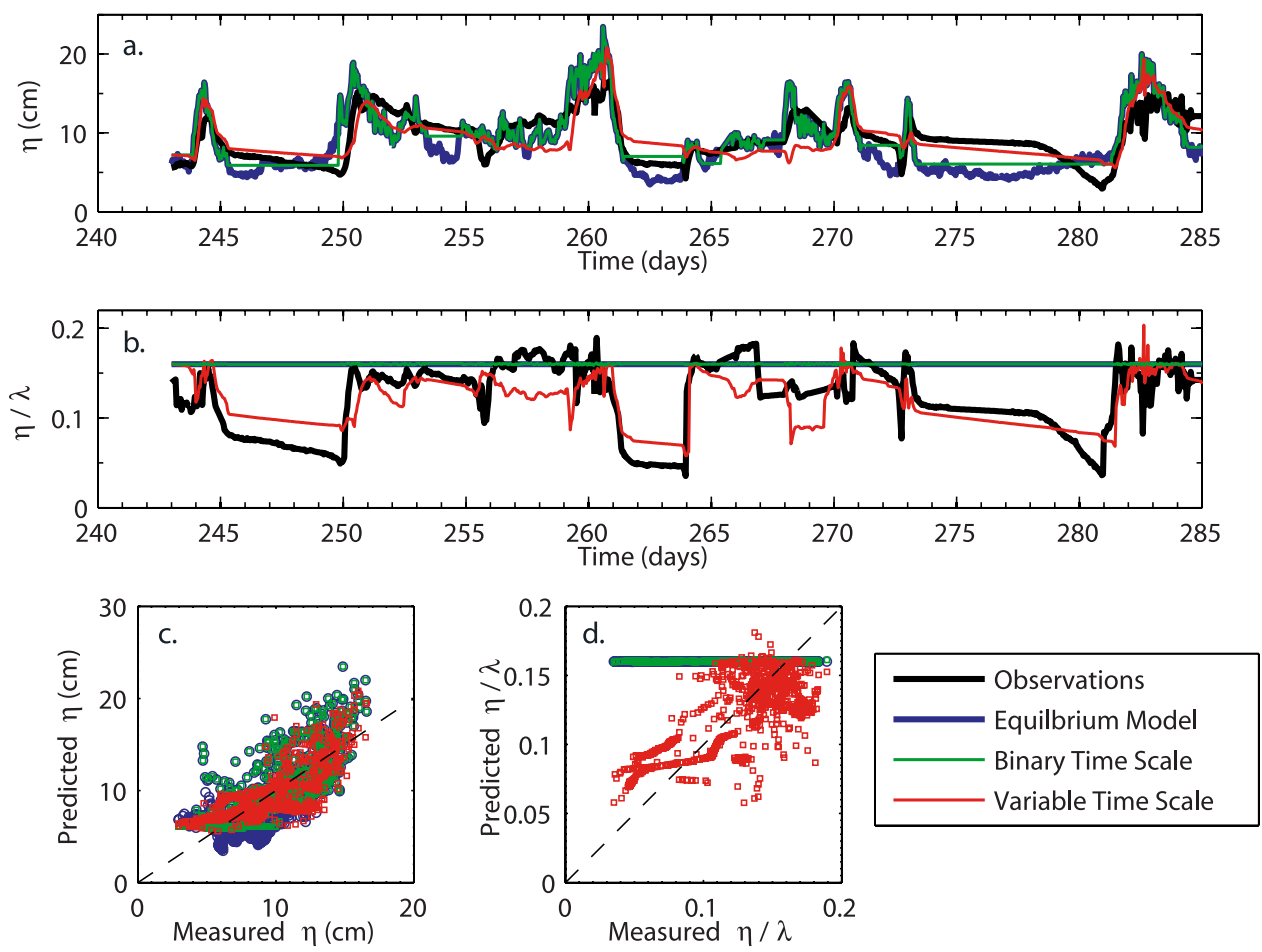

Figure 14. Times series of (a) observed and modeled ripple height $(\eta)$ and (b) ripple steepness $(\eta / \lambda)$ from the MVCO05 data set. Model predictions of (c) ripple height and (d) steepness are plotted against observations in the lower panels.

predictor for both equilibrium and relict conditions. If only equilibrium conditions were considered, the binary timescale and the equilibrium model would perform better.

[36] The variable timescale model predictions have considerable spread about the equilibrium relation both during active and subcritical conditions. During active conditions, when the ripples are not in the suborbital regime (wavelengths of approximately $0.8 \mathrm{~m}$ or greater), this spread appears to be similar for both short and long orbital diameter conditions. This equal spread most likely results from the ripple adjustment timescale remaining relatively long compared to the rapid fluctuations in orbital diameter even at high orbital diameters, due to the large crosssectional areas of the large ripples (Figure 10). This is most visible in the MVCO02 data set (Figure 13c, red dots). The subcritical periods with relict ripples predicted by the model are evident by long horizontal clusters of data points in $\lambda-$ $d_{0}$ parameter space, which occur at all wavelengths from 0.3 to $1.2 \mathrm{~m}$, consistent with the data. While the variable timescale model fills the same portions of parameter space as the data, it does not always do so coherently (i.e., it does not always exactly predict the correct wavelength at the correct time). The variable timescale model produces results with $S E V$ values that are considerably better than the other modeling approaches, but are still occasionally near one (MVCO02). Despite the inability to capture all the details of ripple wavelength fluctuations, the variable timescale modeling approach is clearly the preferred approach for predicting both equilibrium and relict ripple wavelengths in both active and subcritical conditions due to the significantly lower $S E V$ values compared to the other approaches. In particular, the variable timescale is generally able to cor- rectly predict the long wavelength relict ripples observed in the data, and thus represents a significant improvement over the other modeling approaches in this regard.

\subsubsection{Ripple Height and Steepness}

[37] While most of the analysis has focused on ripple wavelength, since all three data sets have high quality measurements of wavelength, the MVCO05 2-axis rotary pencil beam data set provided measurements of ripple height and steepness $(\eta / \lambda)$. The spectral model also provides predictions of ripple height and steepness. The observations show ripple steepness of around 0.15 to 0.17 during active conditions, with lower steepness $(0.05$ to 0.1$)$ during subcritical conditions. The ripple heights follow a similar trend, with heights of 0.10 to $0.15 \mathrm{~m}$ during energetic conditions and 0.05 to $0.10 \mathrm{~m}$ during low-energy conditions (Figure 14). This decrease in ripple steepness in decreasing wave energy conditions (for example, after 245 and 260) is qualitatively similar to the ripple splitting and flattening processes observed in laboratory studies [Testik et al., 2005]. Most of the periods of low steepness are also associated with observed and predicted occurrences of bimodal spectra.

[38] Many of the equilibrium ripple models in the literature suggest that ripples will begin to flatten at Shields numbers over 0.2 [Nielsen, 1981] or $d_{0} / \eta$ over 20 (consistent with suborbital and anorbital ripples, [Wiberg and Harris, 1994]). The MVCO05 data, which is examined in detail in this paper, has Shields numbers slightly over 0.3 and $d_{0} / \eta$ ratios of less than 25; thus it is not expected that the ripples should show a significant decrease in steepness. Other data from MVCO- 05 , which is not included in the time series analysis presented here due to data gaps, show 
Table 2. Standardized Error Variances (SEV) for the Three Different Modeling Approaches for Ripple Height and Steepness With the MVCO05 Data Set

\begin{tabular}{lcc}
\hline & Ripple Height & Ripple Steepness \\
\hline Equilibrium Model & 0.93 & 2.0 \\
Binary Time Scale & $0.68(73 \%)$ & $2.0(100 \%)$ \\
Variable Time Scale & $0.52(56 \%)$ & $0.48(25 \%)$ \\
\hline
\end{tabular}

ripples with a steepness of 0.15 to 0.20 during conditions with Shields numbers of 0.5 to 0.6 . The data with energetic conditions from MVCO02 (Figure 9) also does not show a decrease in steepness, although the height estimates from the rotary side-scan system are of lower quality than the 2axis pencil beam system deployed at MVCO05 [Traykovski et al., 1999]. Since the observations do not show a decrease in steepness during the most energetic conditions, the use of a constant steepness $(\eta / \lambda=0.16)$ in the equilibrium model for the model calculations is justified. The binary timescale model also predicts the same constant steepness because the height of the predicted ripples is always directly related to the wavelength. This results in poor model performance in predicting steepness for both the equilibrium and binary timescale model, which have SEVs for ripple steepness of 2.0 (Table 2). The variable timescale model adjusts the spectral variance of each wave number component with a different timescale, which results in long wavelength relict ripples with relatively low height during subcritical conditions. The performance of this model in predicting steepness $(S E V=0.62)$ is significantly better than the equilibrium or binary timescale models.

[39] Despite the inability of the equilibrium and binary timescale models to predict steepness well, all three models predict ripple height with approximately similar skill, with the equilibrium model being slightly inferior to the other two approaches (Figures 14a and 14c). The equilibrium and binary timescale models both under predict ripple wavelength during subcritical conditions. The combination of the prediction of short wavelength ripples and a constant steepness assumption results in relatively low amplitude ripples during subcritical conditions, while observations low amplitude long wavelength ripples in combination with low amplitude short wavelength ripples (bimodal spectra). The variable timescale model predicts correctly these bimodal spectra with long wavelength peak components during subcritical conditions, resulting in the correct prediction of relatively low integrated ripple heights.

\section{Conclusions}

[40] An extensive data set of ripple observations collected at two locations with medium and coarse sand show that ripple parameters such as wavelength and ripple height are often not in equilibrium with hydrodynamic forcing. The observations were conducted with two different measurement and analysis techniques. While the rotary side-scan technique produces a large field of view ripple planform image rather quickly (or with better averaging for reduced noise), a pencil beam sonar with two stepper motors provides a topographic map of ripple surface elevation from which elevation spectra can be calculated. Both techniques produce estimates of ripple wavelength that scale with wave orbital diameter during moderate energy conditions when the ripples are in equilibrium with hydrodynamic forcing. This orbital scaling, combined with the absence of a reduction in ripple height, steepness, or wavelength at high stresses, suggests that examining the data in terms of the wavelength and orbital diameter parameters $\left(\lambda-d_{0}\right.$ space $)$ is the most useful approach for these ripples. An equilibrium model for these ripples was developed by combining orbital ripple scaling with a suspension threshold to determine the maximum wavelength ripple as the orbital ripples transition into the suborbital regime [Smith and Wiberg, 2006]. This threshold is a function of wave orbital velocity and grain size, while maximum wavelength at the threshold depends on wave orbital diameter. Consequently, this approach depends on orbital velocity, orbital diameter, and grain size, and represents an improvement on previous approaches that depended only on orbital diameter and grain size.

[41] Examining the observations in $\lambda-d_{0}$ space shows that the majority of the nonequilibrium points are long wavelength relict ripples that remain after the peak of the wave event as wave orbital diameters decrease. Three different modeling approaches were compared to better predict ripple parameters in active and subcritical conditions. The first approach assumed that the ripples were in equilibrium at all times, with no ability to predict relict ripples. The second approach forced relict ripples to be preserved with geometry consistent with the equilibrium forcing at the time the stress became subcritical. This approach predicted relict ripples that were considerably shorter than observed. A third modeling approach was developed with a first order differential equation which allows the ripples to lag the forcing by means of a temporally variable adjustment timescale, defined by the ripple cross-sectional area divided by the sediment transport rate. To fit the data, the adjustment timescale was multiplied by a single constant for all three data sets. In both the second and third modeling approaches the ripple spectra are modeled linearly, so that each spectral component is treated independently. The variable timescale model allowed longer wavelength relict ripples to be preserved after wave events, due to the long delay timescales associated with large ripples formed at the peak of a wave event.

[42] The variable timescale model was also able to predict bimodal ripple spectra due to the different timescales associated with small and large ripples. The other modeling approaches can only predict unimodal spectra due to their equilibrium relation with forcing. The ability to predict bimodal spectra is partially a function of the varying temporal adjustment for different wavelength ripple components in the model, and partially due to the temporal evolution of the hydrodynamic forcing. The model will only predict bimodal ripple spectra under certain temporal patterns of hydrodynamic forcing. The observations, other laboratory observations [e.g., Testik et al., 2005] and other types models [Andersen et al., 2001; Werner and Kocurek, 1999] suggest that bimodal spectra may be a phenomenon inherent to ripple dynamics and not dependent on the details of the hydrodynamic forcing. For instance, if the only mechanisms that decrease ripple wavelengths are the growth of new ripples in the troughs of the previous ripples or the along-crest propagation of crest bifurcations, then bimodal 
spectra maybe an intrinsic feature of ripples that are decreasing in wavelength. The equilibrium model that is inherent to this type of model does not account for the possibility that there could be multiple stable ripple states for a given forcing condition. This model, with parameterized scaling relations, does not capture the complexity of these types of nonlinear ripple-ripple interactions. Future work on ripple evolution using three-dimensional coupled numerical hydrodynamic and sediment transport models, as well as additional analysis of the observations could be used to tune the parameter dependence of simplified models such as those presented here. Compared to a coupled numerical hydrodynamic sediment transport model, the parameterized approach employed here is more practical for use as a predictive tool when the input is a long-time series of hydrodynamic conditions. Since this parameterized model can incorporate any equilibrium ripple model, future work could also extend this modeling approach to other conditions and environments where there are significant delays between hydrodynamic forcing and ripple morphologic change.

[43] Acknowledgments. The author would like to thank the support staff of the Martha's Vineyard Coastal Observatory and the LEO-15 observatory for assistance in the deployments. I would also like to thank the captain and crew of the RV Asterias, RV Tioga, and RV Connecticut for their able seamanship in the deployment of the instrumentation. James Irish provided invaluable technical support in developing and maintaining the instrumentation. This work was funded under ONR grants N00014-0110564 and N00014-06-10329 under the direction of program manager Thomas Drake.

\section{References}

Andersen, K. H., M.-L. Chabanol, and M. V. Hecke (2001), Dynamical models for sand ripples beneath surface waves, Phys. Rev. E, 63, 8 .

Ardhuin, F., T. G. Drake, and T. H. C. Herbers (2002), Observations of wave-generated vortex ripples on the North Carolina continental shelf, J. Geophys. Res., 107(C10), 3143, doi:10.1029/2001JC000986.

Ardhuin, F., W. C. O'Reilly, T. H. C. Herbers, and P. F. Jessen (2003), Swell transformation across the continental shelf: Part I. Attenuation and directional broadening, J. Phys. Oceanogr., 33, 1921-1939.

Austin, T. C., J. B. Edson, W. R. McGillis, M. J. P. C. von Alt, R. Petitt, M. K. McElroy, J. Ware, and R. Stokey (2000), The Martha's vineyard coastal observatory: A long term facility for monitoring air-sea processes, paper presented at Proceedings of the Oceans 2000, MTS/IEEE Conferenc.

Chotiros, N. P., D. E. Smith, and J. N. Piper (2002), Refraction and scattering into a sandy ocean sediment in the $30-40-\mathrm{kHz}$ band, IEEE J. Oceanic Eng., 27, 362-375.

Clifton, H. E., and J. R. Dingler (1984), Wave-formed structures and paleoenvironmental reconstruction, Mar. Geol., 60, 165-198.

Craghan, M. (1995), Topographic changes and sediment characteristics at a shoreface sand ridge-Beach Haven Ridge, New Jersey, M.S. thesis, 123 pp., Rutgers University, Rutgers, N. J.

Crawford, A. M., and A. E. Hay (2003), Wave orbital velocity skewness and linear transition ripple migration: Comparison with weakly nonlinear theory, J. Geophys. Res., 108(3), 3091, doi:10.1029/2001JC001254.

Davis, J. P., D. J. Walker, M. Townsend, and I. R. Young (2004), Waveformed sediment ripples: Transient analysis of ripple spectral development, J. Geophys. Res., 109, C07020, doi:10.1029/2004JC002307.

Doucette, J. S., and T. O'Donoghue (2003), Sand ripples in irregular and changing wave conditions: A review of laboratory and field studies, Report for EC MAST Project No. MAS3-CT97-0086 Sandpit project, http://sandpit.wldelft.nl/reportpage/right/SandpitLiteratureReviewVan DerWerf.pdf.

Gibbs, R. J., M. D. Mathews, and D. A. Link (1971), The relationship between sphere size and settling velocity, J. Sediment. Petrol., 41, 7-18.

Goff, J. A., L. A. Mayer, P. Traykovski, I. Buynevich, R. Wilkens, R. Raymond, G. Glang, R. L. Evans, H. Olson, and C. Jenkins (2005), Detailed investigation of sorted bedforms, or "rippled scour depressions," within the Martha's Vineyard Coastal Observatory, Massachusetts, Cont. Shelf Res., 25, 461-484.
Grant, W. D., and O. S. Madsen (1986), The continental-shelf bottom boundary layer, Annu. Rev. Fluid Mech., 18, 265-305.

Hanes, D. M., V. Alymov, and Y. S. Chang (2001), Wave-formed sand ripples at Duck, North Carolina, J. Geophys. Res., 106, 22,575522,592 .

Harris, C. K., and P. L. Wiberg (2001), A two-dimensional, time-dependent model of suspended sediment transport and bed reworking for continental shelves, Comput. Geosci., 27, 675-690.

Hay, A. E., and T. Mudge (2005), Principal bed states during SandyDuck97: Occurrence, spectral anisotropy, and the bed state storm cycle, J. Geophys. Res., 110, C03013, doi:10.1029/2004JC002451.

Hay, A. E., and D. J. Wilson (1994), Rotary sidescan images of nearshore bedform evolution during a storm, Mar. Geol., 119, 57-65.

Hsu, T. J., and D. M. Hanes (2004), Effects of wave shape on sheet flow sediment transport, J. Geophys. Res., 109, C05025, doi:10.1029/ 2003JC002075.

Hsu, T. J., and B. Raubenheimer (2006), A numerical and field study on inner-surf and swash sediment transport, Cont. Shelf Res., 26, 589-598.

Jackson, D. R., K. L. Williams, E. I. Thorsos, and S. G. Kargl (2002), High-frequency subcritical acoustic penetration into a sandy sediment, IEEE J. Oceanic Eng., 27, 346-361.

Lesser, G., J. Kester, and J. A. Roelvink (2000), Report Z3899, Delft Hydraulics, Delft, Netherlands.

Li, M. Z., and C. L. Amos (2001), SEDTRANS96: The upgraded and better calibrated sediment-transport model for continental shelves, Comput. Geosci., 27, 619-645.

Madsen, O. S., Y.-K. Poon, and H. C. Graber (1988), Spectral Wave Attenuation by Bottom Friction: Theory, paper presented at Proceedings of the 21st International Conference on Coastal Engineering, Am. Soc. of Civ. Eng., New York.

Meyer-Peter, E., and R. Muller (1948), Formulas for bed-load transport, paper presented at Paper presented at 3rd Meeting. IAHR, Int. Assoc. Hydraul. Res., Stockholm.

Ngusaru, A. S., and A. E. Hay (2004), Cross-shore migration of lunate megaripples during Duck94, J. Geophys. Res., 109, C02006, doi:10.1029/ 2002JC001532.

Nielsen, P. (1981), Dynamics and geometry of wave-generated ripples, J. Geophys. Res., 86, 6467-6472.

Precht, E., and M. Huettel (2004), Rapid wave-driven advective pore water exchange in a permeable coastal sediment, J. Sea Res., 51, $93-107$

Richardson, M. D., and P. Traykovski (2002), Real-time observations of mine burial at the Martha's Vineyard Coastal Observatory, paper presented at Proceedings of the 5th International Symposium on Technology and the Mine Problem, Naval Postgraduate School, Monterey California, 22-25 May.

Smith, D., and J. F. A. Sleath (2005), Transient ripples in oscillatory flows, Cont. Shelf Res., 25, 485-501.

Smith, J. J., and P. L. Wiberg (2006), Ripple Geometry in Wave-Dominated Environments Revisited, paper presented at Eos Trans. AGU, 87(36), Ocean Sci. Meet. Suppl., Abstract OS35D-24.

Smyth, C., and A. E. Hay (2002), Wave friction factors in nearshore sands, J. Phys. Oceanogr., 32, 3490-3498.

Smyth, C. E., and M. Z. Li (2005), Wave-current bedform scales, orientation, and migration on Stable Island Bank, J. Geophys. Res., 110, C02023, doi:10.1029/2004JC002569.

Soulsby, R. L., and R. J. S. Whitehouse (2005), Prediction of ripple properties in shelf seas. Mark 1 predictor, Report TR150, Release 1.1, produced by HR Wallingford Ltd, UK for the ONR Ripples DRI Program, http:// www.hrwallingford.co.uk/downloads/projects/ripples/TR150 ripples.pdf.

Styles, R., and S. M. Glenn (2002), Modeling bottom roughness in the presence of wave-generated ripples, J. Geophys. Res., 107(C8), 3110, doi:10.1029/2001JC000864.

Sumer, B. M., and J. Fredsøe (2002), The Mechanics of Scour in the Marine Environment, World Scientific, Singapore.

Swart, D. H. (1974), Offshore sediment transport and equilibrium beach profiles, p. 302, Delft Hydraulics Laboratory, Delft, Netherlands.

Terray, E. A., R. L. Gordon, and B. H. Brumley (1997), Measuring wave height and direction using upward-looking ADCPs, paper presented at Proc. of Oceans'97. Oceans'97 MTS/IEEE.

Testik, F. Y., S. I. Voropayev, and H. J. S. Fernando (2005), Adjustment of sand ripples under changing water waves, Phys. Fluids, 17, 072,104072,108

Traykovski, P., A. E. Hay, J. D. Irish, and J. F. Lynch (1999), Geometry, migration, and evolution of wave orbital ripples at LEO-15, J. Geophys. Res., 104, 1505-1524.

Trembanis, A. C., C. T. Friedrichs, M. Richardson, P. A. Traykovski, and P. Howd (2007), Predicting seabed burial of cylinders by wave-induced scour: Application to the sandy inner shelf off Florida and Massachusetts, IEEE J. Oceanic Eng., in press. 
Voropayev, S. I., G. B. McEachern, D. L. Boyer, and H. J. S. Fernando (1999), Dynamics of sand ripples and burial/scouring of cobbles in oscillatory flow, Appl. Ocean Res., 21, 249-261.

Voropayev, S. I., F. Y. Testik, H. J. S. Fernando, and D. L. Boyer (2003), Morphodynamics and cobbles behavior in and near the surf zone, Ocean Eng., 30, $1741-1764$.

Warner, J. C., C. R. Sherwood, R. P. Signell, C. K. Harris, and H. Arango (2007), Development of a three-dimensional, regional, coupled wave-, current-, and sediment-transport model, Comput. Geosci., in review.

Werner, B. T., and G. Kocurek (1999), Bedform spacing from defect dynamics, Geology, 27, 727-730.

Wheatcroft, R. A. (1994), Temporal variation in bed configuration and one-dimensional bottom roughness at the mid-shelf STRESS site, Cont. Shelf Res., 14, 1167-1190.
Whitehouse, R. (1998), Scour at Marine Structures: A Manual for Practical Applications, 198 pp., Thomas Telford Publications, London.

Wiberg, P. L., and C. K. Harris (1994), Ripple geometry in wave-dominated environments, J. Geophys. Res., 99, 775-789.

Williams, J. J., P. S. Bell, and P. D. Thorne (2005), Unifying large and small wave-generated ripples, J. Geophys. Res., 110, C02008, doi:10.1029/ 2004JC002513.

P. Traykovski, Applied Ocean Physics and Engineering Department, Woods Hole Oceanographic Institution, Woods Hole, MA 02543, USA. (ptraykovski@whoi.edu) 